\title{
Torsional vibrational structure of the propene radical cation studied by high-resolution photoelectron spectroscopy
}

\author{
Journal Article \\ Author(s): \\ Vasilatou, Konstantina; Merkt, Frédéric \\ Publication date: \\ 2011-09-28 \\ Permanent link: \\ https://doi.org/10.3929/ethz-a-010781022
}

Rights / license:

In Copyright - Non-Commercial Use Permitted

Originally published in:

The Journal of Chemical Physics 135(12), https://doi.org/10.1063/1.3638182

Funding acknowledgement:

135342 - Rydberg states, VUV laser spectroscopy and photoionization dynamics (SNF) 
This article may be downloaded for personal use only. Any other use requires prior permission of the author and AIP Publishing.

The following article appeared in J. Chem. Phys. 135, 124310 (2011) and may be found at http://dx.doi.org/10.1063/1.3638182. 


\section{AD| $\begin{aligned} & \text { The Journal of } \\ & \text { Chemical Physics }\end{aligned}$}

Torsional vibrational structure of the propene radical cation studied by high-resolution photoelectron spectroscopy

K. Vasilatou and F. Merkt

Citation: The Journal of Chemical Physics 135, 124310 (2011); doi: 10.1063/1.3638182

View online: http://dx.doi.org/10.1063/1.3638182

View Table of Contents: http://scitation.aip.org/content/aip/journal/jcp/135/12?ver=pdfcov

Published by the AIP Publishing

\section{Articles you may be interested in}

The cyclopropene radical cation: Rovibrational level structure at low energies from high-resolution photoelectron spectra

J. Chem. Phys. 141, 064317 (2014); 10.1063/1.4890744

The $\mathrm{X}+2 \Pi \mathrm{g}, \mathrm{A}+2 \Pi \mathrm{u}, \mathrm{B}+2 \Delta \mathrm{u}$, and $\mathrm{a}+\Sigma \mathrm{u}-4$ electronic states of $\mathrm{Cl} 2+$ studied by high-resolution photoelectron spectroscopy

J. Chem. Phys. 139, 034302 (2013); 10.1063/1.4812376

Photoelectron spectroscopic study of the $E \otimes e$ Jahn-Teller effect in the presence of a tunable spin-orbit interaction. I. Photoionization dynamics of methyl iodide and rotational fine structure of $\mathrm{CH} 3 \mathrm{I}+$ and $\mathrm{CD} 3 \mathrm{I}+$ J. Chem. Phys. 134, 054308 (2011); 10.1063/1.3547548

Infrared-vacuum ultraviolet-pulsed field ionization-photoelectron study of $\mathrm{C} \mathrm{H} 3 \mathrm{I}$ + using a high-resolution infrared laser

J. Chem. Phys. 128, 104306 (2008); 10.1063/1.2888557

Diradicals, antiaromaticity, and the pseudo-Jahn-Teller effect: Electronic and rovibronic structures of the cyclopentadienyl cation

J. Chem. Phys. 127, 034303 (2007); 10.1063/1.2748049

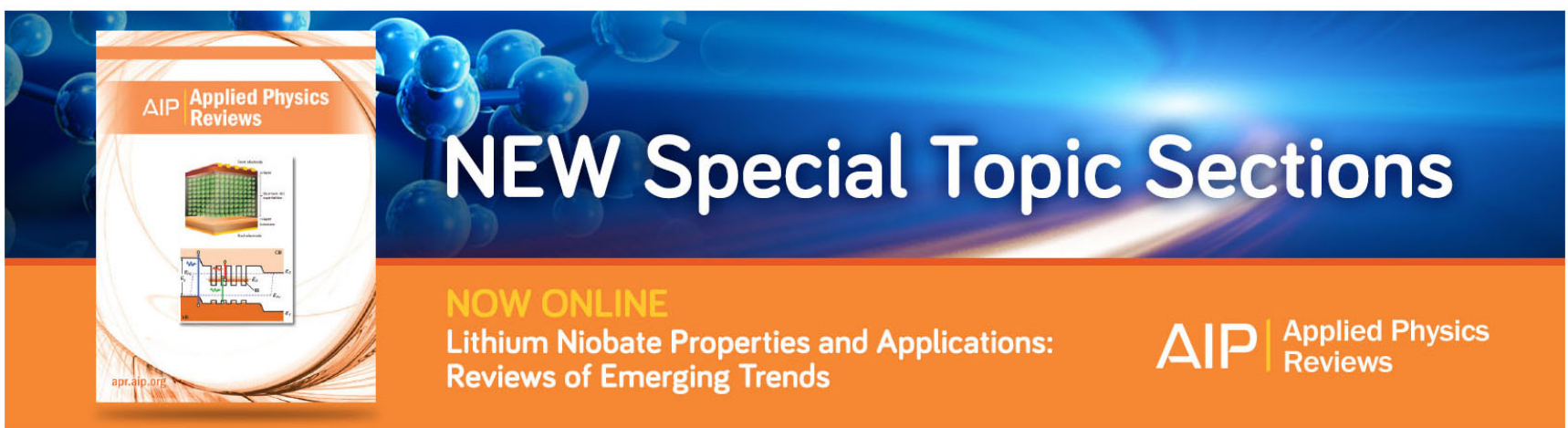




\title{
Torsional vibrational structure of the propene radical cation studied by high-resolution photoelectron spectroscopy
}

\author{
K. Vasilatou and F. Merkt ${ }^{\mathrm{a})}$ \\ Laboratorium für Physikalische Chemie, ETH Zürich, CH-8093 Zurich, Switzerland
}

(Received 19 July 2011; accepted 24 August 2011; published online 30 September 2011)

\begin{abstract}
The pulsed-field-ionization zero-kinetic-energy photoelectron spectra of the $\widetilde{\mathrm{X}}^{+2} \mathrm{~A}^{\prime \prime} \leftarrow \widetilde{\mathrm{X}}^{1} \mathrm{~A}^{\prime}$ transition of $\mathrm{CH}_{3} \mathrm{CHCH}_{2}$ (propene), $\mathrm{CD}_{3} \mathrm{CDCD}_{2}$, and several partially deuterated isotopomers have been recorded in the region of their adiabatic ionization thresholds and up to $2000 \mathrm{~cm}^{-1}$ of internal energy of the cations. The vibrational structure has been assigned on the basis of the frequency shifts resulting from deuteration of selected sites of the propene molecule. Two highly anharmonic progressions have been identified and assigned to the two torsional modes of the propene cation, the methyl and methylene torsions. The positions of the torsional levels could be approximately reproduced using one-dimensional models, allowing a semi-quantitative description of the potential energy surface along each torsional coordinate. The observation of forbidden vibrational bands and the analysis of their partially resolved rotational contours reveal the importance of the vibronic coupling between the $\widetilde{\mathrm{X}}^{+2} \mathrm{~A}^{\prime \prime}$ and the $\widetilde{\mathrm{A}}^{+2} \mathrm{~A}^{\prime}$ states mediated by the methylene $\left(v_{20}\right)$ and methyl $\left(v_{21}\right)$ torsional modes. (C) 2011 American Institute of Physics. [doi:10.1063/1.3638182]
\end{abstract}

\section{INTRODUCTION}

Propene is a small hydrocarbon of relevance to atmospheric chemistry and astrophysics ${ }^{1,2}$ and of multiple industrial uses. Propene is also the simplest molecule having a single methyl rotor adjacent to a carbon-carbon double bond and has therefore been the object of several theoretical and experimental studies aiming at a better understanding of the hindered internal rotation of the methyl group. ${ }^{3-12}$

The far-infrared spectrum of propene was measured by Fateley and Miller $^{3}$ in the context of a much broader and thorough investigation of the torsional spectra of molecules having a methyl rotor. From the analysis of the spectrum, the parameters $V_{3}$ and $V_{6}$ describing the potential energy along the methyl torsional coordinate as a Fourier series were determined for the $\widetilde{\mathrm{X}}^{1} \mathrm{~A}^{\prime}$ ground state of propene. Möller et al. ${ }^{4}$ measured the spectrum at higher resolution and succeeded in partially resolving the $K_{a}$ structure of the main torsional band. Persisting ambiguities in the analysis of the vibrational structure of propene at higher energies were clarified by Silvi et $a l .^{5}$ who measured the IR and Raman spectra of four isotopic species of propene between $200 \mathrm{~cm}^{-1}$ and $4000 \mathrm{~cm}^{-1}$. Durig et al.$^{6}$ recorded both the Raman and far-infrared spectra of propene, analyzed the $K_{a}$ structure and used the results to characterize the torsional motion.

Propene has also been studied extensively by microwave spectroscopy. Lide and Mann ${ }^{7}$ analyzed the microwave spectra of propene and $\mathrm{CH}_{3}^{13} \mathrm{CHCH}_{2}$, determined the structure of the molecule, and estimated the torsional potential barrier from the tunneling splittings observed in the microwave spectrum of the ground state. The complete substitution structure of propene $\left(r_{\mathrm{s}}\right)$ was derived by Lide and Christensen ${ }^{8}$ from the microwave spectra of seven singly-substituted iso-

\footnotetext{
${ }^{a)}$ Electronic mail: feme@xuv.phys.chem.ethz.ch.
}

topomers and was further refined by Hirota and Morino ${ }^{9}$ who analyzed the spectra of several doubly-deuterated species. A very detailed investigation of the internal rotation of propene has been reported by Hirota ${ }^{10}$ who also observed and analyzed the tunneling splittings in the first two excited torsional levels. More recently, the measurements have been extended to the millimeter-wave and submillimeter-wave regions of the electromagnetic spectrum. ${ }^{11,12}$

The data obtained from microwave and far-infrared studies are complementary. Resolving the line splittings arising from the methyl internal rotation in the ground vibrational state allows for an estimation of the barrier height $V_{3}$. The parameter $V_{6}$, which is the coefficient of the next member of the Fourier-series expansion of the torsional potential, can only be derived if excited torsional states are observed, either in the far-infrared or in the microwave spectra. To interpret a torsional spectrum in the far-infrared region, the reduced internal rotation constant $F$ is needed, which can be derived from the geometrical structure of the molecule as determined from microwave studies. An important aspect of the methyl internal rotation is that it almost always represents a complex motion and not just a pure torsion, and $a b$ initio calculations are essential to predict which nuclear motions are coupled to the methyl internal rotation. ${ }^{13}$

In contrast to the considerable efforts invested in the characterization of the neutral species, only little experimental information is available on the propene radical cation. The photoelectron spectrum of the ground cationic state of propene has been recorded at low energy by Burrill and Johnson ${ }^{14}$ at a resolution sufficient to observe the vibrational structure. The spectrum consists of many partially overlapping spectral features which renders the assignment of the vibrational structure challenging. Moreover, because of the pronounced anharmonicity of the torsional modes, harmonic frequencies calculated $a b$ initio cannot be used to reliably predict the 
(a)<smiles>C=CC</smiles>

(c)

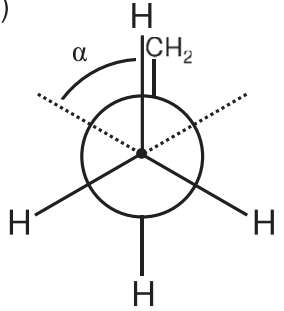

(b)

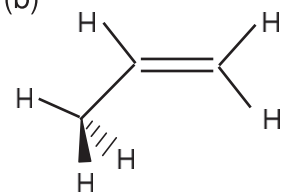

(d)

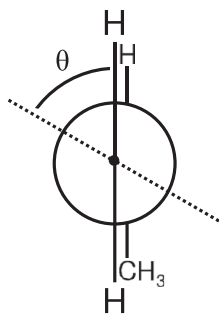

FIG. 1. Schematic representation of the eclipsed (a) and staggered (b) conformations of propene. (c) and (d) Definition of the torsional angles $\alpha$ and $\theta$ for the $\mathrm{CH}_{3}$ and $\mathrm{CH}_{2}$ torsions, respectively. The structures displayed in (c) and (d) correspond to the minimum energy geometries.

positions of the excited torsional states of the propene radical cation. Several assignments proposed in Ref. 14 are ambiguous. For example, the assignment of a vibrational level observed at $\sim 621 \mathrm{~cm}^{-1}$ above the ground state of $\mathrm{CH}_{3} \mathrm{CHCH}_{2}^{+}$ to the second overtone of the methyl-torsional mode $\left(21^{3}\right)$ indicates a surprisingly large anharmonicity (in Ref. 14, the fundamental $\left(21^{1}\right)$ and the first overtone $\left(21^{2}\right)$ were reported to be at $\sim 94 \mathrm{~cm}^{-1}$ and $\sim 213 \mathrm{~cm}^{-1}$, respectively).

The almost complete lack of experimental data on the propene radical cation stands in contrast to the fact that this cation, in particular the height of the torsional barrier along the $\mathrm{CH}_{3}$-internal rotation coordinate, has been used as a reference system in the discussion of conformational preferences in molecules having $\mathrm{CH}_{3}-\mathrm{CH}=\mathrm{X}$ functionalities (see Refs. 15 and 16 and in particular also Refs. 17 and 18 for reviews of the early literature). Questions that resulted in much debate are (i) whether the energetically most stable conformation is the eclipsed [Fig. 1(a)] or the staggered [Fig. 1(b)] one, and (ii) what the actual physical or chemical reasons are for the preference of specific conformations in specific electronic states of the neutral and singly-charged anions and cations and in the presence of specific $\mathrm{X}$ groups (e.g., $\mathrm{X}=\mathrm{O}, \mathrm{NH}, \mathrm{CH}_{2}$ ).

As often the case in physical-organic chemistry, many possible, and not necessarily mutually exclusive explanations can be invoked, such as, in the case of the conformational stability of the $\mathrm{CH}_{3}-\mathrm{CH}=\mathrm{X}$ molecules, the destabilization of the staggered conformation by the interaction between the fully occupied $\pi_{\mathrm{CH}_{3}}$ and $\pi_{\mathrm{C}=\mathrm{X}}$ orbitals, the stabilization of the eclipsed conformation by the interaction between the $\pi_{\mathrm{CH}_{3}}$ and $\pi_{\mathrm{C}=\mathrm{X}}^{*}$ orbitals, the opposite effects from $\pi_{\mathrm{CH}_{3}}^{*}-\pi_{\mathrm{C}=\mathrm{X}}^{*}$ interactions, the destabilization resulting from the partial fourelectron cycles with anti-aromatic character, and the destabilization resulting from the interaction between the central $\mathrm{CH}$ bond and the methyl $\mathrm{CH}$ bond that is "eclipsed" in the staggered conformation [see Fig. 1(b)]. The discussion of these effects, which can to some extent be rationalized by $a b$ initio quantum chemical calculations, contributes to sharpen chemists' intuition concerning molecular structure.

The development of pulsed-field-ionization zero-kineticenergy (PFI-ZEKE) photoelectron spectroscopy ${ }^{19}$ and the continual improvement of the resolution that can be achieved with this technique ${ }^{20-22}$ makes it possible to obtain information on the methyl-torsional motion of molecular cations $^{14,23,24}$ and to study in detail the effects of removing an electron from bonding $\pi_{\mathrm{CC}}$ orbitals. ${ }^{25-27}$ The questions concerning the relative stability of the eclipsed and staggered conformations of cations containing $\mathrm{CH}_{3}-\mathrm{CH}=\mathrm{X}$ functionalities can now be answered experimentally. For instance, Kim and his co-workers ${ }^{28,29}$ have exploited mass-analyzed thresholdionization spectroscopy to study the methyl-torsional motion in $\mathrm{CH}_{3}-\mathrm{CX}=\mathrm{CH}_{2}^{+}(\mathrm{X}=\mathrm{Cl}, \mathrm{Br})$ and found that the eclipsed form [Fig. 1(a)] is favored both in the neutral and the cation, but that the barrier is very strongly reduced (to $\left.\sim 50-100 \mathrm{~cm}^{-1}\right)$ in the cations compared to the neutrals $\left(\sim 1000 \mathrm{~cm}^{-1}\right)$.

The electronic ground state of the propene radical cation has an unpaired electron in the $2 a^{\prime \prime}$ molecular orbital, which is a bonding $\pi_{\mathrm{CC}}$ orbital. Compared to the ground state of the neutral, one therefore expects more torsional flexibility along the bond connecting the $\mathrm{HC}$ and $\mathrm{CH}_{2}$ groups. The propene radical cation should possess two low-frequency, possibly coupled, torsional modes and thus represents an ideal molecular system to study the effects of torsional motions along two adjacent bonds. Photoelectron spectroscopy is well suited to characterize these motions because changes in the torsional potentials that result from ionization lead to the observation of vibrational progressions in the corresponding modes, an advantage that was well demonstrated by the previous investigation by Burrill and Johnson. ${ }^{14}$

The general aim of the present work was to characterize and model the vibrational energy level structure of the propene cation at low energies and so obtain a better understanding of the large-amplitude torsional motions. More specific goals were (i) to resolve ambiguities in previous assignments of the low-lying vibrational levels of the propene radical cation by recording photoelectron spectra of several deuterated isotopomers and systematically analyzing the isotopic shifts, (ii) to derive quantitative information on the potential energy surface along the torsional modes, primarily in the form of barrier heights and widths and verify theoretical predictions concerning the relative energies of the conformers and the torsional barrier along the $\mathrm{CH}_{3}$ internal rotation coordinate, and (iii) to gain information on vibronic interactions in the cation that could complement that obtained in our previous study of the rotational structure of the vibrational ground state, ${ }^{30}$ and in studies of vibronic interactions in the ground state of $\mathrm{C}_{2} \mathrm{H}_{4}^{+} \cdot 25,26,31,32$

\section{EXPERIMENTAL}

The photoelectron spectra of propene and its deuterated isotopomers were recorded using a vacuum ultraviolet (VUV) laser system with a bandwidth of about $0.2 \mathrm{~cm}^{-1}$. ${ }^{33}$ The VUV radiation was generated by resonance-enhanced differencefrequency mixing $\left(\widetilde{v}_{\mathrm{VUV}}=2 \widetilde{v}_{1}-\widetilde{v}_{2}\right)$ in krypton using two tunable dye lasers. The wave number $\widetilde{v}_{1}$ of the tripled output of the first dye laser was held fixed at the position 
$2 \widetilde{v}_{1}=94092.86 \mathrm{~cm}^{-1}$ of the $(4 \mathrm{p})^{5}\left({ }^{2} \mathrm{P}_{3 / 2}\right) 5 \mathrm{p}[1 / 2](J$ $=0) \leftarrow(4 \mathrm{p})^{6}\left({ }^{1} \mathrm{~S}_{0}\right)$ two-photon resonance of krypton, and the VUV wave number was scanned by tuning the wave number $\widetilde{v}_{2}$ of the second dye laser, which was calibrated using an optogalvanic cell. The VUV wave number was determined with an accuracy of about $0.5 \mathrm{~cm}^{-1}$ by calculating the difference $\left(2 \widetilde{v}_{1}-\widetilde{v}_{2}\right)$.

Propene- $h_{6}$ (>99\% purity) and propene- $d_{6}$ (isotopic purity of 99\%) were purchased from Aldrich and Isotec, respectively, and were used without further purification. The partially deuterated isotopomers were synthesized following instructions found in the literature $e^{34-36}$ and purified to a level of better than $99 \%$ as determined by high-pressure liquid chromatography. The identity of the isotopomers was verified by time-of-flight mass spectrometry and photoionization spectroscopy (see gray traces in Fig. 2 below).

Mixtures of about 10\%-20\% propene in Ar were introduced into the chamber through a pulsed nozzle operated at a stagnation pressure of $\sim 3$ bar and used to form a supersonic expansion. The supersonic beam was skimmed and subsequently intersected the VUV laser beam at right angles in the photoionization region where the rotational temperature was estimated to be $\sim 10 \mathrm{~K}$ from the rotational contours of the observed bands of the photoelectron spectra.

To achieve high resolution in the photoelectron spectra, a multipulse electric-field sequence, ${ }^{21}$ delayed by $2.0 \mu \mathrm{s}$ relative to the time of photoexcitation was applied. The electric fields also accelerated the electrons toward a microchannelplate detector located at the end of a magnetically shielded time-of-flight tube. The pulse sequence consisted typically of three electric field steps: a positive discrimination pulse of $90 \mathrm{mV} / \mathrm{cm}$ and $1 \mu \mathrm{s}$ duration, followed immediately by two successive 250-ns-long negative extraction pulses of $-70 \mathrm{mV} / \mathrm{cm}$ and $-107 \mathrm{mV} / \mathrm{cm}$. Two time gates were set at the positions corresponding to the times of flight of the electrons produced by these two extraction pulses and the integrated electron signals were recorded as a function of the laser wave number and stored in a personal computer. A good compromise between high resolution and signal-to-noise ratio was reached in the spectra obtained with the $-107 \mathrm{mV} / \mathrm{cm}$ field pulse. A correction of $(+1.25 \pm 0.3) \mathrm{cm}^{-1}$ was introduced to compensate for the field-induced shift of the ionization thresholds. ${ }^{21}$ The overview spectra were recorded as described above, but with a simpler two-pulse electric-field sequence consisting of a $90 \mathrm{mV} / \mathrm{cm}$ discrimination pulse followed by a $-900 \mathrm{mV} / \mathrm{cm}$ extraction pulse necessitating a correction of $(+2.2 \pm 0.50) \mathrm{cm}^{-1}$.

\section{RESULTS AND DISCUSSION}

\section{A. General considerations}

The equilibrium geometry of propene in the $\widetilde{\mathrm{X}}^{1} \mathrm{~A}^{\prime}$ ground electronic state has been found to be $C_{\mathrm{s}} \cdot{ }^{13}$ The ground-state electronic configuration is ...( $\left(1 a^{\prime \prime}\right)^{2}\left(9 a^{\prime}\right)^{2}\left(10 a^{\prime}\right)^{2}\left(2 a^{\prime \prime}\right)^{2}$. The HOMO orbital $\left(2 a^{\prime \prime}\right)$ has a nodal plane containing the three carbon atoms and is predominantly a $\pi$ orbital with $\mathrm{C}=\mathrm{C}$ bonding character. Ionization out of this orbital gives rise to the $\widetilde{\mathrm{X}}^{+2} \mathrm{~A}^{\prime \prime}$ ground electronic state of the cation. Ab initio calculations ${ }^{14}$ indicate that the plane of symmetry is preserved upon ionization out of this orbital so that the equilibrium geometry of the cation is predicted to be of $C_{\mathrm{s}}$ symmetry, although more sophisticated ab initio calculations would be needed to verify this prediction. Propene has 21 nondegenerate normal modes, 14 of $a^{\prime}$ and 7 of $a^{\prime \prime}$ symmetry. The lowest frequency modes in the case of the propene radical cation are the $v_{21}\left(a^{\prime \prime}\right)$ and $\nu_{20}\left(a^{\prime \prime}\right)$ normal modes, corresponding predominantly to the methyl internal rotation and the $\mathrm{CH}_{2}$ torsion, respectively, followed by the $\mathrm{CCC}$ bending mode $v_{14}\left(a^{\prime}\right)$. These modes are energetically well separated from the higher frequency modes so that their numbering does not change upon isotopic substitution. The other vibrational modes of the cation are labeled by indicating the main component of the motion to avoid confusion arising from changes in the numbering of the modes of the different isotopomers.

Upon removal of an electron from the $2 a^{\prime \prime}$ molecular orbital, the $\mathrm{C}=\mathrm{C}$ bond strength is expected to be weakened and the torsional flexibility enhanced. Ab initio calculations predict an increase of the $\mathrm{C}=\mathrm{C}$ bond length from 1.336 $\pm 0.004 \AA$ (Ref. 8) to about $1.4169 \AA \AA^{14}$ Based on chemical intuition and the Franck-Condon principle, one expects vibrational progressions to be observed in all three low-frequency modes mentioned above, and also in the $\mathrm{C}=\mathrm{C}$ stretching, the $\mathrm{CH}_{2}$ deformation and the $\mathrm{CH}$ bending modes. Consequently, the photoelectron spectrum of the $\widetilde{\mathrm{X}}^{+} \leftarrow \widetilde{\mathrm{X}}$ transition of propene has a high density of bands even at low energies and its assignment represents a challenge.

In the photoelectron spectra of the $\widetilde{\mathrm{X}}^{+} \leftarrow \widetilde{\mathrm{X}}$ transition of propene ${ }^{14}$ and its deuterated isotopomers (see Fig. 2 below) the origin band is by far the most intense. The weakness of the low-frequency bands necessitated the use of a large field-ionization pulse $(0.9 \mathrm{~V} / \mathrm{cm})$ which limited the experimental resolution to about $1 \mathrm{~cm}^{-1}$. Consequently, no rotational structure could be observed for these bands that would have allowed the unambiguous determination of the vibronic symmetry of the cationic levels using rovibronic photoionization selection rules, as was possible for the origin band. ${ }^{30}$ To nevertheless assign the vibrational structure, the photoelectron spectra of several deuterated isotopomers of propene, $\mathrm{CH}_{3} \mathrm{CDCH}_{2}, \mathrm{CH}_{3} \mathrm{CHCD}_{2}, \mathrm{CD}_{3} \mathrm{CHCH}_{2}$, and $\mathrm{CD}_{3} \mathrm{CDCD}_{2}$, were also recorded and the identity of each vibrational band was deduced from the magnitude of the isotope shifts. Indeed, the Franck-Condon active modes are expected to be unambiguously identifiable by the isotopic shifts caused by deuteration at specific carbon sites. The anticipated effects of such deuterations are summarized in Table I from which one can conclude, for instance, that the $21^{1}$ levels of all $\mathrm{CH}_{3}$-containing isotopomers should be located at approximately the same energy but above the energy of the $21^{1}$ levels of the $\mathrm{CD}_{3}$-containing isotopomers. In favorable cases, the analysis of the rotational contours of the vibrational bands enabled us to independently confirm the assignments made on the basis of isotopic shifts.

The overview PFI-ZEKE photoelectron spectra of the $\widetilde{\mathrm{X}}^{+2} \mathrm{~A}^{\prime \prime}\left(v_{i}^{v_{i}}\right) \leftarrow \widetilde{\mathrm{X}}^{1} \mathrm{~A}^{\prime}\left(0^{0}\right)$ transitions of (a) $\mathrm{CH}_{3} \mathrm{CHCH}_{2}$, (b) $\mathrm{CH}_{3} \mathrm{CDCH}_{2}$, (c) $\mathrm{CH}_{3} \mathrm{CHCD}_{2}$, (d) $\mathrm{CD}_{3} \mathrm{CHCH}_{2}$, and (e) $\mathrm{CD}_{3} \mathrm{CDCD}_{2}$ in the wave number range from $78500 \mathrm{~cm}^{-1}$ to 

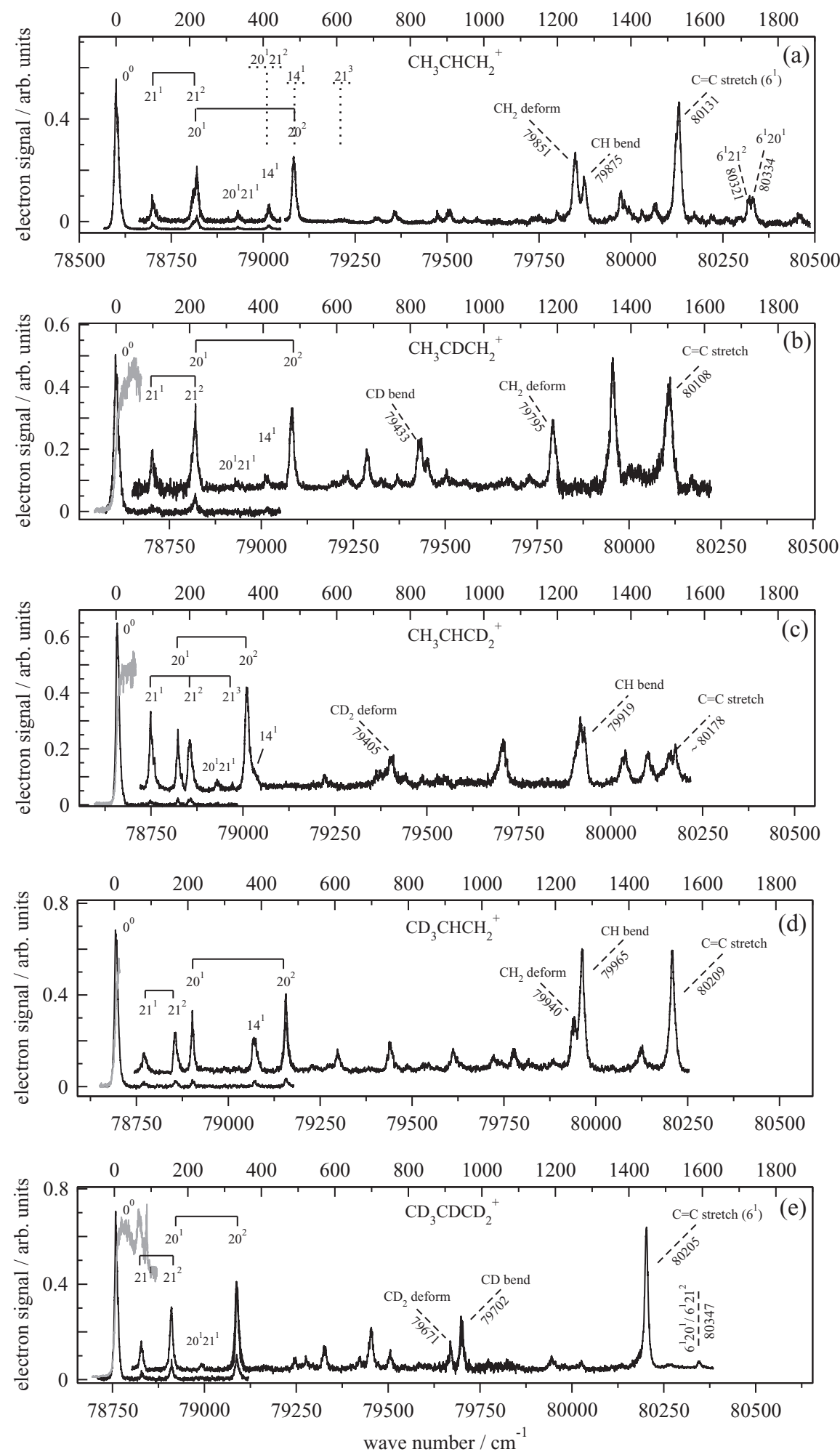

FIG. 2. Survey PFI-ZEKE photoelectron spectra of the $\tilde{\mathrm{X}}^{+} \leftarrow \tilde{\mathrm{X}}$ transition in (a) $\mathrm{CH}_{3} \mathrm{CHCH}_{2}$, (b) $\mathrm{CH}_{3} \mathrm{CDCH}_{2}$, (c) $\mathrm{CH}_{3} \mathrm{CHCD}_{2}$, (d) $\mathrm{CD}_{3} \mathrm{CHCH}_{2}$, and (e) $\mathrm{CD}_{3} \mathrm{CDCD}_{2}$. The gray traces correspond to the photoionization spectra. The assignments of the vibrational bands in $\mathrm{CH}_{3} \mathrm{CHCH}_{2}$ of $\mathrm{Ref} 14$ that differ from ours are indicated by dotted vertical lines in panel (a). The assignments of the bands at high energy are tentative and are indicated by dashed diagonal lines.

$80500 \mathrm{~cm}^{-1}$ are presented in Fig. 2. In each panel, the bottom horizontal axis corresponds to the VUV wave number, and the top horizontal axis to the internal wave number of the cations. The gray traces correspond to the photoionization spectra, obtained by monitoring the ion yield as a function of the VUV wave number. The sharp and strong rise of the photoionization signal from the zero level at the positions where the first bands in the PFI-ZEKE photoelectron spectra are observed confirms that these are the origin bands $\left(0_{0}^{0}\right)$ of the corresponding isotopomers. 
TABLE I. Anticipated magnitude of the isotopic shifts resulting from deuteration at specific carbon sites of the propene radical cation.

\begin{tabular}{|c|c|c|c|c|c|c|}
\hline Deuteration & $\begin{array}{c}\mathrm{CH}_{3} \text { torsion } \\
v_{21}\left(a^{\prime \prime}\right)\end{array}$ & $\begin{array}{c}\mathrm{CH}_{2} \text { torsion } \\
v_{20}\left(a^{\prime \prime}\right)\end{array}$ & $\begin{array}{c}\text { CCC bend } \\
v_{14}\left(a^{\prime}\right)\end{array}$ & $\begin{array}{c}\mathrm{C}=\mathrm{C} \text { stretch } \\
a^{\prime}\end{array}$ & $\begin{array}{c}\mathrm{CH}_{2} \text { deform. } \\
a^{\prime}\end{array}$ & $\begin{array}{c}\mathrm{CH} \text { bend } \\
a^{\prime}\end{array}$ \\
\hline $\mathrm{CH}_{3} \leftrightarrow \mathrm{CD}_{3}$ & Strong & Vanishing & Weak & Vanishing & Vanishing & Vanishing \\
\hline $\mathrm{CH} \leftrightarrow \mathrm{CD}$ & Vanishing & Vanishing & Vanishing & Vanishing & Vanishing & Strong \\
\hline $\mathrm{CH}_{2} \leftrightarrow \mathrm{CD}_{2}$ & Vanishing & Strong & Weak & Weak & Strong & Vanishing \\
\hline
\end{tabular}

The assignments of the vibrational bands indicated in Fig. 2 were obtained from the analysis of the isotopic shifts on the basis of the expectations summarized in Table I. The assignments and the spectral positions are presented in Table II. As will be discussed in more detail in Secs. III BIII D, they are in agreement with the results of ab initio quantum chemical calculations, and, in the case of the two torsional modes $\nu_{20}$ and $v_{21}$, they are supported by predictions made in the realm of simple one-dimensional models for the torsional motions.

To facilitate the discussion of the vibrational level structure of the propene radical cation and its deuterated isotopomers presented in Secs. III B and III C, we chose to give the experimentally determined positions relative to the ground state of the ion rather than to the ground state of the neutral molecules as directly measured in the PFI-ZEKE photoelectron spectra. This choice necessitated the determination of the adiabatic ionization energies of each isotopomer at a higher accuracy than the full widths at half maximum of typically $10-15 \mathrm{~cm}^{-1}$ of the rotational contours of the origin bands.

In our previous study of the rotational structure of $\mathrm{CH}_{3} \mathrm{CHCH}_{2}$ and $\mathrm{CD}_{3} \mathrm{CDCD}_{2}$, the adiabatic ionization energies of these two isotopomers were determined to be $78602.0(4) \mathrm{cm}^{-1}$ and $78759.9(5) \mathrm{cm}^{-1}$, respectively. ${ }^{30}$ To determine the adiabatic ionization energies of $\mathrm{CH}_{3} \mathrm{CDCH}_{2}$, $\mathrm{CH}_{3} \mathrm{CHCD}_{2}$ and $\mathrm{CD}_{3} \mathrm{CHCH}_{2}$, the PFI-ZEKE photoelectron spectra of their origin bands were measured at higher resolution, as explained in Sec. II, and the partially resolved rotational structures were analyzed with the procedure described in Ref. 30. The high-resolution spectra of $\mathrm{CH}_{3} \mathrm{CDCH}_{2}$, $\mathrm{CH}_{3} \mathrm{CHCD}_{2}$ and $\mathrm{CD}_{3} \mathrm{CHCH}_{2}$ are displayed in Fig. 3, where the position of the adiabatic ionization energy is indicated by a vertical dotted line centered at the origin of the wave-number scale. The values of the adiabatic ionization energies derived from the analysis of the partially resolved rotational structures are summarized in Table III. The uncertainties of $1 \mathrm{~cm}^{-1}$ or less make an insignificant contribution to the uncertainties of $3 \mathrm{~cm}^{-1}$ or more in the positions of the vibrational levels of the cations determined from the photoelectron spectra displayed in Fig. 2 (see Table II).

\section{B. The low-frequency modes $v_{21}$ (methyl torsion), $v_{20}$ (methylene torsion), and $v_{14}$ (CCC bend)}

The assignments of all bands in Fig. 2 was carried out by exploiting the facts that (1) deuteration of the methyl (methylene) group does not strongly affect any vibrational progressions in this region except the methyl (methylene) torsion, and (2) deuteration of the methyl and methylene groups both induce a weak shift of the $\mathrm{C}-\mathrm{C}-\mathrm{C}$ bending levels towards lower wave number (see Table I). The information contained in the photoelectron spectra of all five isotopomers of propene depicted in Fig. 4 turned out to be necessary for an unambiguous assignment because of an accidental overlap of the positions of the fundamental $\left(20^{1}\right)$ of the methylene torsion and the first overtone $\left(21^{2}\right)$ of the methyl torsion in $\mathrm{CH}_{3} \mathrm{CHCH}_{2}$ (trace (a)), $\mathrm{CH}_{3} \mathrm{CDCH}_{2}$ (trace (b)) and $\mathrm{CD}_{3} \mathrm{CDCD}_{2}$ (trace (e)). Indeed, without the spectra of $\mathrm{CH}_{3} \mathrm{CHCD}_{2}$ (trace (c)) and $\mathrm{CD}_{3} \mathrm{CHCH}_{2}$ (trace (d)), it would have been much more difficult to recognize, and prove, that the $20_{0}^{1}$ and $21_{0}^{1}$ bands, which are nominally forbidden by symmetry in the $\widetilde{\mathrm{X}}^{+2} \mathrm{~A}^{\prime \prime} \leftarrow \widetilde{\mathrm{X}}^{1} \mathrm{~A}^{\prime}$ photoionizing transition, make a significant contribution to the intensity distributions as a result of vibronic interactions. The assignments of all bands observed in Fig. 4 and summarized in Table II are now discussed separately for each progression.

\section{The methyl torsion $\left(v_{21}\right)$}

According to the $a b$ initio calculations of Burrill and Johnson $^{14}$ and also to those carried out at the UMP2/6$311 \mathrm{G}(2 \mathrm{~d}, \mathrm{p})$ level in the realm of the present study, the methyl torsion is the lowest-frequency mode of the propene cation, with a fundamental wave number expected at a position of $\sim 90 \mathrm{~cm}^{-1}$ and $\sim 70 \mathrm{~cm}^{-1}$ above the ground state in $\mathrm{CH}_{3}$ and $\mathrm{CD}_{3}$-containing isotopes, respectively. In their investigation of the photoelectron spectrum of $\mathrm{CH}_{3} \mathrm{CHCH}_{2}$, Burrill et al. assigned bands located $94 \mathrm{~cm}^{-1}, 213 \mathrm{~cm}^{-1}$ and $621 \mathrm{~cm}^{-1}$ above the origin to the $21^{1}, 21^{2}$, and $21^{3}$ levels of $\mathrm{CH}_{3} \mathrm{CHCH}_{2}^{+}$, however, without discussion of the fact that the $21_{0}^{1}$ and $21_{0}^{3}$ bands are forbidden by symmetry.

The analysis of our spectra confirms the former two assignments, but suggests a different assignment for the $21^{3}$ level. The $21^{1}$ levels of all $\mathrm{CH}_{3}$-containing isotopomers of the propene cations are observed at positions in the range $90-100 \mathrm{~cm}^{-1}$ above the respective origins and those of the two $\mathrm{CD}_{3}$-containing isotopomers in the range $70-80 \mathrm{~cm}^{-1}$, leaving no doubt that they correspond to the methyl torsion. Initially, we were tempted to assign these bands to the first overtone $\left(21_{0}^{2}\right)$ of the methyl torsion because of the forbidden nature of the $21_{0}^{1}$ band; however, our attempts to model the torsional motions on the basis of this assignment (see Sec. III D) were unsuccessful and consistently indicated $21_{0}^{1}$ as the only possible assignment.

The $21^{2}$ levels of the $\mathrm{CH}_{3}$ - and $\mathrm{CD}_{3}$-containing isotopomers of the propene cation are observed in the ranges $200-220 \mathrm{~cm}^{-1}$ and $150-160 \mathrm{~cm}^{-1}$, respectively. However, as mentioned above, the accidental near degeneracy of the $21^{2}$ and $20^{1}$ levels in $\mathrm{CH}_{3} \mathrm{CHCH}_{2}^{+}, \mathrm{CH}_{3} \mathrm{CDCH}_{2}^{+}$and $\mathrm{CD}_{3} \mathrm{CDCD}_{2}^{+}$ complicates the assignments. The spectra of $\mathrm{CH}_{3} \mathrm{CHCD}_{2}^{+}$and 
TABLE II. Band centers (in $\left.\mathrm{cm}^{-1}\right)^{\mathrm{a}}$, experimental and calculated vibrational wave numbers and assignment of the low-lying vibrational levels of the propene radical cation and several of its deuterated isotopomers.

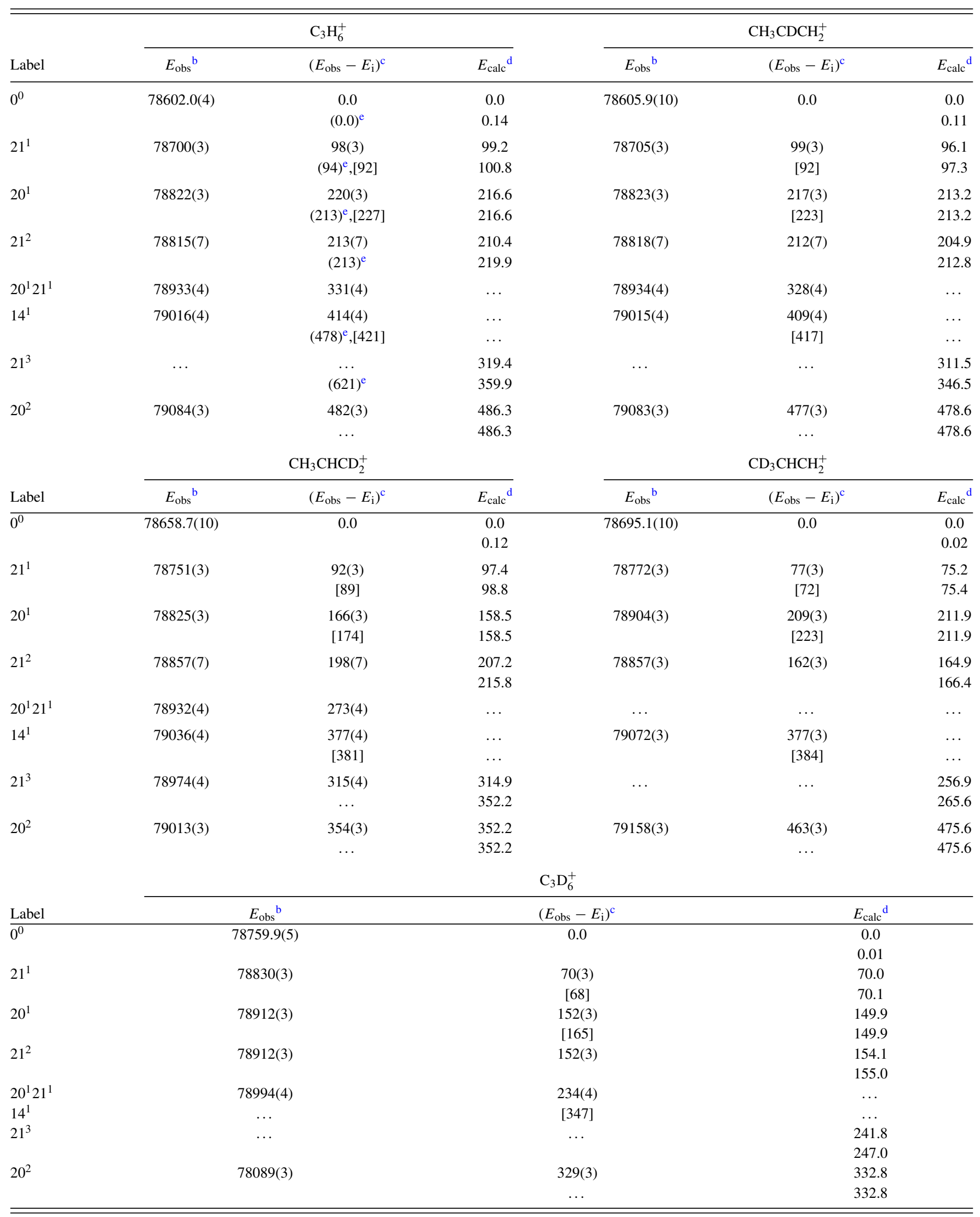

${ }^{\mathrm{a}}$ Only the transition wave numbers observed in the spectral region from the ionization threshold and up to $500 \mathrm{~cm}^{-1}$ of internal energy are listed in this table.

${ }^{\mathrm{b}}$ Corrected for the field-induced shift of the ionization energy.

${ }^{\mathrm{c}}$ The harmonic vibrational wave numbers calculated $a b$ initio at the level of UMP2/6-311(2p,d) are given in square brackets.

${ }^{\mathrm{d}}$ Vibrational wave numbers of the torsional levels calculated using a simple one-dimensional model (see text for more details).

${ }^{\mathrm{e}}$ Assignments proposed in Ref. 14. 
TABLE III. Adiabatic ionization energies of propene and its deuterated isotopomers.

\begin{tabular}{cccccc}
\hline \hline & $\mathrm{C}_{3} \mathrm{H}_{6}$ & $\mathrm{CH}_{3} \mathrm{CDCH}_{2}$ & $\mathrm{CH}_{3} \mathrm{CHCD}_{2}$ & $\mathrm{CD}_{3} \mathrm{CHCH}_{2}$ & $\mathrm{C}_{3} \mathrm{D}_{6}$ \\
\hline$E_{\mathrm{i} / \mathrm{cm}^{-1 \mathrm{a}}}$ & $78602.0(4)$ & $78605.9(10)$ & $78658.7(10)$ & $78695.1(10)$ & $78759.9(5)$ \\
Ref. & 30 & This work & This work & This work & 30 \\
\hline \hline
\end{tabular}

${ }^{a}$ The values of the adiabatic ionization energies have been corrected for the field-induced shift. The numbers in parentheses represent the estimated uncertainties.

$\mathrm{CD}_{3} \mathrm{CHCH}_{2}^{+}$represent the key to the assignment because the $20^{1}$ level of the former isotopomer and the $21^{2}$ level of the latter one are shifted to lower wave numbers. The shifts enable the observation of both levels as distinct bands in Fig. 4 [see traces (c) and (d)]. The spectrum of $\mathrm{CD}_{3} \mathrm{CHCH}_{2}^{+}$[trace

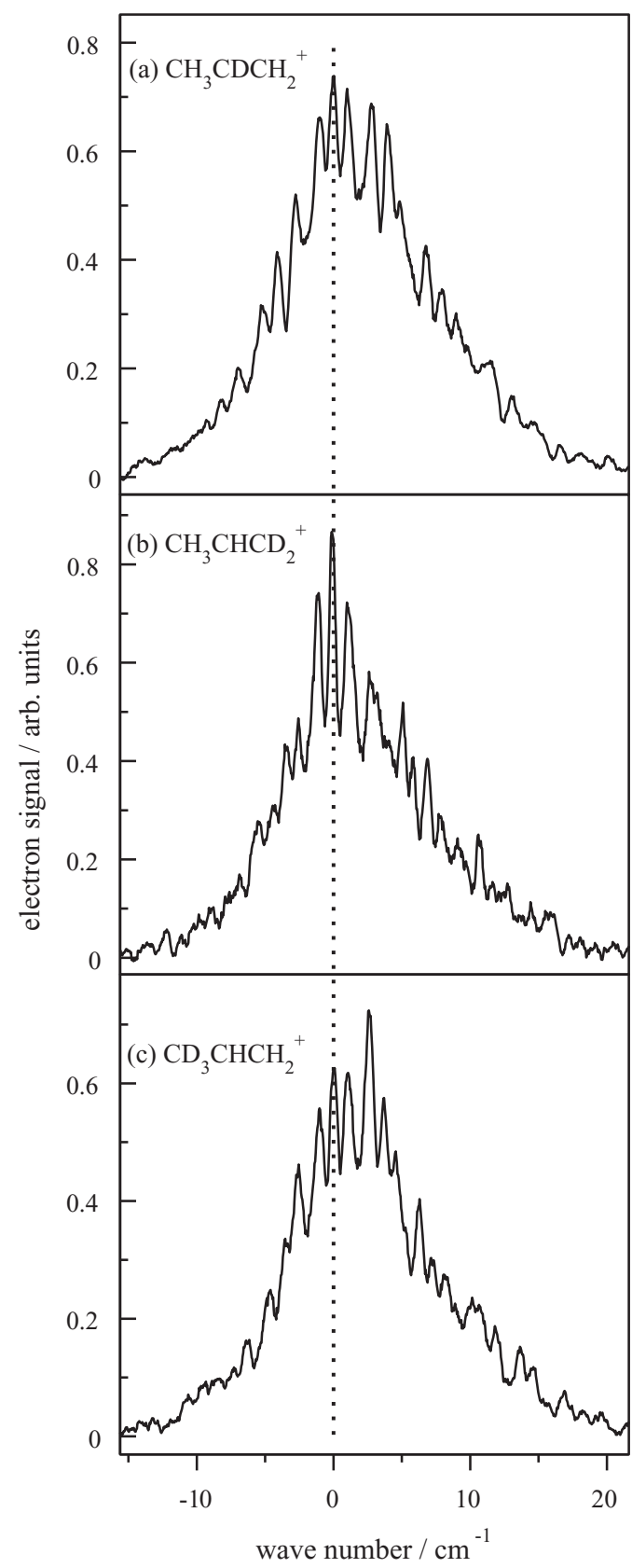

FIG. 3. High-resolution PFI-ZEKE photoelectron spectra of the origin bands of (a) $\mathrm{CH}_{3} \mathrm{CDCH}_{2}$, (b) $\mathrm{CH}_{3} \mathrm{CHCD}_{2}$, and (c) $\mathrm{CD}_{3} \mathrm{CHCH}_{2}$. The bands have been aligned so that their centers coincide at the origin. (d) in Fig. 4] is particularly instructive because it enables the observation of the $21^{2}$ level in isolation from any other vibrational bands of $a^{\prime}$ symmetry that could perturb the intensity of the $21_{0}^{2}$ photoelectron band. The spectrum shows the $21_{0}^{2}$ band to be about 2.5 times more intense than the $21_{0}^{1}$ band, which highlights the Franck-Condon forbidden, but vibronically allowed, nature of the $21_{0}^{v}$ bands with odd $v$ values. Intensity perturbations by torsion-rotation coupling, as observed, for instance, in toluene, ${ }^{37}$ and which can be very significant near the top of the barrier, are not expected to be dominant in the present case. The observation of different lineshapes for the $20_{0}^{1}$ and $21_{0}^{2}$ bands in Figs. 4(c) and 4(d) lends further support to our assignment and provides information on the vibronic coupling mechanism, as will be discussed in Sec. III E.

Higher members of the methyl torsional progressions are too weak to be observed in our spectra with the exception of the spectrum of $\mathrm{CH}_{3} \mathrm{CHCD}_{2}^{+}$which could be recorded with a particularly high signal-to-noise ratio. As will be explained in more detail in Subsection III D, we assign the very weak line observed at $315 \mathrm{~cm}^{-1}$ in trace (c) of Fig. 4 to the lower tunneling component of the $21^{3}$ level that is located close to the maximum of the potential barrier along the methyl torsional coordinate. In their study of the photoelectron spectrum of undeuterated propene, Burrill and Johnson ${ }^{14}$ assigned a level observed at $621 \mathrm{~cm}^{-1}$ to the $21^{3}$ level. The assignment of this level, which is also observed as a very weak band in our spectrum, is incompatible with our observations, which instead suggest the $20^{2} 21^{1}$ combination band as a possible, more plausible assignment.

\section{The methylene torsion $\left(v_{20}\right)$ and the CCC bend $\left(v_{14}\right)$}

Upon removal of an electron from the outermost occupied orbital of $a^{\prime \prime}$ symmetry, which has a dominant $\pi_{\mathrm{CC}}$ bonding character, the $\pi_{\mathrm{CC}}$ bond is weakened and the torsional flexibility around this bond enhanced, as mentioned above. One of the consequences is a very strong reduction of the fundamental wave number of the $\mathrm{CH}_{2}$ torsional mode from $990 \mathrm{~cm}^{-1}$ in the ground state of $\mathrm{CH}_{3} \mathrm{CHCH}_{2}{ }^{5}$ to only about $230 \mathrm{~cm}^{-1}$ in the ground state of $\mathrm{CH}_{3} \mathrm{CHCH}_{2}^{+}$according to $a b$ initio calculations (see Table II). This prediction is confirmed by our analysis which identifies the fundamental of the methylene torsion at $\sim 220 \mathrm{~cm}^{-1}$ in the $\mathrm{CH}_{2}$-containing isotopomers and at $\sim 160 \mathrm{~cm}^{-1}$ in the $\mathrm{CD}_{2}$-containing isotopomers (see Table II and Fig. 4).

The first overtone of the methylene torsion can also readily be assigned on the basis of isotopic shifts to the spectral features observed at $\sim 470 \mathrm{~cm}^{-1}$ and $\sim 350 \mathrm{~cm}^{-1}$ in the $\mathrm{CH}_{2}$ - and $\mathrm{CD}_{2}$-containing isotopomers, respectively. Like the 


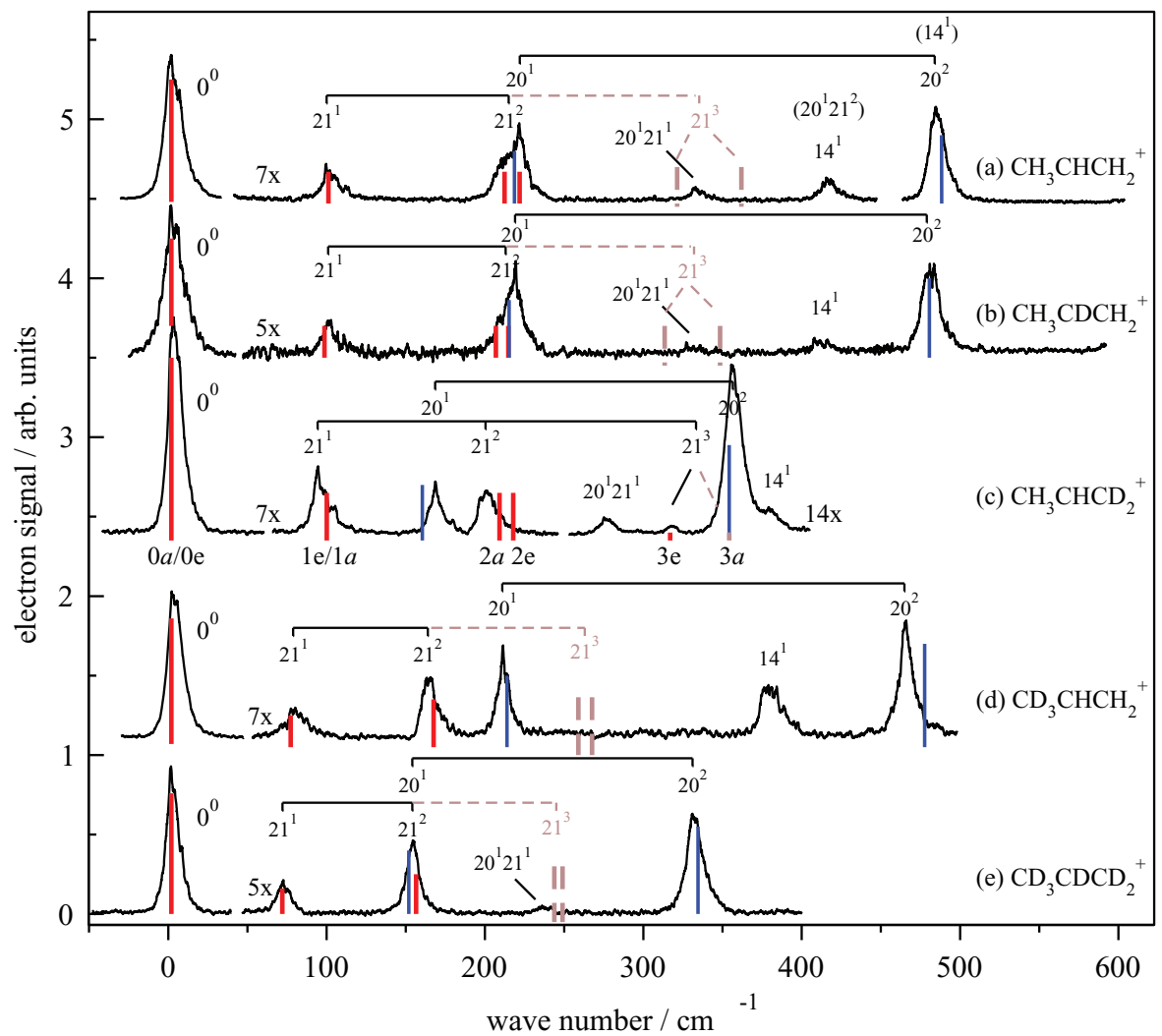

FIG. 4. Enlarged view of the PFI-ZEKE photoelectron spectra of propene at low energies. The stick spectra indicate the calculated positions of the methyl and methylene torsional levels in (a) $\mathrm{CH}_{3} \mathrm{CHCH}_{2}$, (b) $\mathrm{CH}_{3} \mathrm{CDCH}_{2}$, (c) $\mathrm{CH}_{3} \mathrm{CHCD}_{2}$, (d) $\mathrm{CD}_{3} \mathrm{CHCH}_{2}$, and (e) $\mathrm{CD}_{3} \mathrm{CDCD}_{2}$ according to one-dimensional torsional models (see text for details). In trace (a), the assignments of Ref. 14 that differ from ours are given in parentheses. The dashed lines indicate the parts of the progressions that were not observed experimentally but are predicted by our one-dimensional model.

methyl torsional mode, the methylene torsional mode of the propene cation is thus also characterized by a positive anharmonicity, which indicates that the potential along these torsional modes is flat in the vicinity of the minima. The spectra of $\mathrm{CH}_{3} \mathrm{CHCD}_{2}$ and $\mathrm{CD}_{3} \mathrm{CHCH}_{2}$, which enable the observation of the $20^{1}$ and $20^{2}$ levels of the cations as isolated spectral features, indicate that the $20_{0}^{2}$ band is about twice as strong as the $20_{0}^{1}$ band. As explained above, the $20_{0}^{1}$ band is forbidden by symmetry. The observed intensity distribution thus betrays a vibronic interaction between the $\widetilde{\mathrm{X}}^{+2} \mathrm{~A}^{\prime \prime}$ ground state of the propene cation and a higher lying ${ }^{2} \mathrm{~A}^{\prime}$ electronic state mediated by the methylene torsion (see Sec. III E for a more detailed discussion).

Our assignment of the $20_{0}^{2}$ band at $482 \mathrm{~cm}^{-1}$ in the photoelectron spectrum of $\mathrm{CH}_{3} \mathrm{CHCH}_{2}$ differs from that proposed by Burrill and Johnson who have assigned it to the $14_{0}^{1}$ band on the basis of a harmonic wave number of $420 \mathrm{~cm}^{-1}$ calculated ab initio for the CCC bending mode. ${ }^{14}$ Our spectra (see Fig. 4) indicate that the $14_{0}^{1}$ band of $\mathrm{CH}_{3} \mathrm{CHCH}_{2}$ corresponds to the band observed at $414 \mathrm{~cm}^{-1}$, which Burrill and Johnson have assigned to the $20_{0}^{1} 21_{0}^{2}$ combination band.

Our spectra only enable the observation of a single combination band, $20_{0}^{1} 21_{0}^{1}$, which is observed at $78933 \mathrm{~cm}^{-1}$ in the spectrum of $\mathrm{CH}_{3} \mathrm{CHCH}_{2}$ [Fig. 2(a), $331 \mathrm{~cm}^{-1}$ of internal energy in the cation] and is subject to the isotopic shifts anticipated on the basis of the spectra of the other isotopomers (see Figs. 2 and 4 and Table I). This assignment indicates a positive anharmonic shift in the range $12-14 \mathrm{~cm}^{-1}$ which indicates that the two torsional modes are coupled.

\section{Assignments of other modes}

Because of the existence of several low-frequency vibrational modes in the propene cation, the density of the vibrational levels increases rapidly with increasing wave number. Numerous perturbations result which render a detailed analysis of the spectrum at the resolution achieved in our investigation impossible. Consequently, we only present here a tentative interpretation and qualitative analysis of the main spectral features observed at internal energies of the cations beyond the first members of the torsional progressions discussed in Secs. III A and III B.

\section{The $\mathrm{C}=\mathrm{C}$ stretching mode}

In all spectra presented in Fig. 2, except that of $\mathrm{CH}_{3} \mathrm{CHCD}_{2}$ (panel (c)), an intense line is observed in the wave-number range between $1450 \mathrm{~cm}^{-1}$ and $1550 \mathrm{~cm}^{-1}$. This line can be assigned to the fundamental of the $\mathrm{C}=\mathrm{C}$ stretching mode, $6^{1}$, on the basis of the very weak isotopic shifts observed upon deuteration (see Table I). The spectrum of $\mathrm{CH}_{3} \mathrm{CHCD}_{2}^{+}$reveals two lines in this region, so that the $6^{1}$ level of this isotopomer appears to be perturbed by a closelying $a^{\prime}$ vibrational level with which it shares its intensity. 
TABLE IV. Band centers, experimental and calculated ${ }^{\mathrm{a}}$ vibrational wave numbers and their assignment for the propene radical cation and several of its deuterated isotopomers at high energies.

\begin{tabular}{|c|c|c|c|c|c|}
\hline & $\mathrm{C}_{3} \mathrm{H}_{6}$ & $\mathrm{CH}_{3} \mathrm{CDCH}_{2}$ & $\mathrm{CH}_{3} \mathrm{CHCD}_{2}$ & $\mathrm{CD}_{3} \mathrm{CHCH}_{2}$ & $\mathrm{C}_{3} \mathrm{D}_{6}$ \\
\hline \multirow{2}{*}{$\mathrm{CH}_{2}$ rock } & 79851 & 79795 & 79405 & 79940 & 79671 \\
\hline & 1249 [1240] & 1189 [1228] & 746 [801] & 1245 [1221] & 911 [954] \\
\hline \multirow[t]{2}{*}{$\mathrm{CH}$ bend } & 79875 & 79433 & 79919 & 79965 & 79702 \\
\hline & 1273 [1287] & 827 [834] & 1260 [1302] & 1270 [1297] & 942 [970] \\
\hline \multirow[t]{2}{*}{$6^{1}$} & 80131 & 80108 & 80178 & 80209 & 80205 \\
\hline & 1529 [1599] & 1502 [1577] & 1519 [1572] & 1514 [1586] & 1445 [1498] \\
\hline \multirow[t]{2}{*}{$6^{1} 21^{2}$} & 80321 & $\ldots$ & $\ldots$ & $\ldots$ & 80347 \\
\hline & 1719 & & & & 1587 \\
\hline \multirow[t]{2}{*}{$6^{1} 20^{1}$} & 80334 & $\ldots$ & $\ldots$ & $\ldots$ & 80347 \\
\hline & 1732 & & & & 1587 \\
\hline
\end{tabular}

${ }^{a}$ The numbers in square brackets are the harmonic wave numbers calculated $a b$ initio at the UMP2/6-311G(2d,p) level.

Weak bands observed at around $1720 \mathrm{~cm}^{-1}\left(80321 \mathrm{~cm}^{-1}\right)$ and $1600 \mathrm{~cm}^{-1}\left(80347 \mathrm{~cm}^{-1}\right)$ in the spectra of $\mathrm{CH}_{3} \mathrm{CHCH}_{2}^{+}$ (panel (a)) and $\mathrm{CD}_{3} \mathrm{CDCD}_{2}^{+}$(panel (e)), respectively, are assigned to the combination bands $6_{0}^{1} 21_{0}^{2}$ and $6_{0}^{1} 20_{0}^{1}$ because their positions relative to the $6_{0}^{1}$ band correspond closely to the positions of the $21^{2}$ and $20^{1}$ levels relative to the respective ground states of the cations. These assignments are summarized in Table IV.

\section{The $\mathrm{CH}_{2}$-deformation and $\mathrm{CH}$-bending mode}

The spectra of $\mathrm{CH}_{3} \mathrm{CHCH}_{2}^{+}$and $\mathrm{CD}_{3} \mathrm{CHCH}_{2}^{+}$in panels (a) and (d) of Fig. 2 display a doublet between $1200 \mathrm{~cm}^{-1}$ and $1300 \mathrm{~cm}^{-1}$, which shifts to the region between $900 \mathrm{~cm}^{-1}$ and $950 \mathrm{~cm}^{-1}$ upon full deuteration (panel (e)). Deuteration at the central (panel (b)) or methylenic (panel (c)) positions results in a shift to lower wave number of only one of the two lines. From Table I, one can conclude that the corresponding vibrational motions involve primarily the $\mathrm{CH}-\mathrm{CH}_{2}$ part of the molecule. The general considerations presented in Subsection III A further enable us to assign these two bands to the fundamentals of the $\mathrm{CH}_{2}$-deformation and $\mathrm{CH}$-bending modes. Harmonic wave numbers obtained in ab initio calculations performed at the UMP2/6-311G(2d,p) level (see Table IV) support these assignments.

The fundamental of the $\mathrm{CH}(\mathrm{CD})$ bending mode in $\mathrm{CH}_{3} \mathrm{CDCH}_{2}^{+}$and $\mathrm{CH}_{3} \mathrm{CHCD}_{2}^{+}$and of the $\mathrm{CD}_{2}$ deformation mode in $\mathrm{CH}_{3} \mathrm{CHCD}_{2}^{+}$are observed within clusters of transitions, which results in ambiguities and additional uncertainties in their positions. The wave numbers listed in Table IV correspond, in each case, to the intensity maxima of the line clusters indicated by the dashed lines in Fig. 2.

\section{One-dimensional models for the methyl and methylene torsional motions in the propene cation}

The photoelectron spectra of propene and several deuterated isotopomers presented in Secs. III A-III C are dominated, at low energies, by two vibrational progressions in the methyl $\left(v_{21}\right)$ and methylene $\left(v_{20}\right)$ torsional modes, which both reveal a positive anharmonicity. The positive anharmonic shifts of the $20^{1} 21^{1}$ levels further indicate a significant an- harmonic coupling between these modes. Our data, however, do not contain sufficient information on combination levels $20^{v} 21^{v^{\prime}}$ to justify a two-dimensional modeling of the coupled methyl and methylene motions. However, the observation of the fundamental and the first overtone of both modes, and in the case of $\mathrm{CH}_{3} \mathrm{CHCD}_{2}^{+}$the tentative assignment of the second overtone $21^{3}$ of the methyl torsion, make it possible to obtain a semi-quantitative estimate of the potential barriers separating the equivalent equilibrium structures along these torsional motions in the realm of simple one-dimensional models. Clearly, the significance of one-dimensional models of the coupled torsional motions in a molecular ion such as propene must not be overestimated; their main merits are (1) to offer qualitative insights on the effect of photoionization on the torsional flexibility in a simple alkene and (2) to provide supporting evidence for the spectral assignments differing from earlier assignments.

In the case of the methyl internal rotation, the Hamiltonian for the one-dimensional motion is given by the expression

$$
\hat{H}=-F \frac{\partial^{2}}{\partial \alpha^{2}}+V(\alpha),
$$

where $\alpha$ is the internal-rotation angle defined in Fig. 1(c) and $F$ is the reduced rotational constant accounting for the motion of the methyl rotor around the axis of the methyl group

$$
F=\hbar^{2} / 2 r I_{\alpha}
$$

The quantity $r I_{a}$ is interpreted as the reduced moment of inertia of the internal rotation of the $\mathrm{CH}_{3}$ group relative to the rigid molecular frame, ${ }^{38-40} r$ being a reduction factor defined as

$$
r=1-\sum \frac{\lambda_{g}{ }^{2} \cdot I_{\alpha}}{I_{g}}
$$

$I_{\alpha}$ is the moment of inertia of the methyl top about its symmetry axis, $I_{g}(g=a, b, c)$ are the principal moments of inertia fixed in the frame part of the molecule, and $\lambda_{g}$ are the direction cosines between the top axis and the principal axes. $V(\alpha)$ is the one-dimensional torsional potential function, which has a period of $2 \pi / N$ and can therefore be represented by a 
TABLE V. Experimentally determined and ab initio calculated ${ }^{\S}$ potential energy parameters for the methyl internal rotation and the $\mathrm{CH}_{2}$ torsion in propene and the propene radical cation.

\begin{tabular}{|c|c|c|c|c|c|}
\hline \multicolumn{3}{|c|}{ Neutral $\left(\widetilde{\mathrm{X}}^{1} \mathrm{~A}^{\prime}\right)$} & \multicolumn{3}{|c|}{ Cation $\left(\widetilde{\mathrm{X}}^{+2} \mathrm{~A}^{\prime \prime}\right)$} \\
\hline \multicolumn{6}{|c|}{$\mathrm{CH}_{3}$ torsion } \\
\hline$V_{3} / \mathrm{cm}^{-1}$ & $V_{6} / \mathrm{cm}^{-1}$ & Ref. & $V_{3} / \mathrm{cm}^{-1}$ & $V_{6} / \mathrm{cm}^{-1}$ & Ref. \\
\hline 708.5 & -21.2 & 6 & 429 & & $14^{\S}$ \\
\hline 693.7 & -14.0 & 6 & 395.3 & & $29^{\S}$ \\
\hline $692.4 \pm 6$ & & 7 & & & \\
\hline $698.4 \pm 0.5$ & $-13 \pm 2$ & 10 & $A^{\mathrm{a}} / \mathrm{cm}^{-1}$ & $c^{\mathrm{a}} /$ degrees & Ref. \\
\hline 682.9 & -4.78 & 45 & 400 & 17 & This work \\
\hline 689.1 & $-13.5^{\mathrm{b}}$ & $13^{\S}$ & & & \\
\hline 684.7 & & $29^{\S}$ & & & \\
\hline \multicolumn{6}{|c|}{$\mathrm{CH}_{2}$ torsion } \\
\hline & & & $\mathrm{A}^{\mathrm{a} / \mathrm{cm}^{-1}}$ & $\mathrm{c}^{\mathrm{a} / \mathrm{deg} r e e s}$ & Ref. \\
\hline & & & $8000\left(-\mathrm{CH}_{2}\right)$ & 23 & This work \\
\hline & & & $8900\left(-\mathrm{CD}_{2}\right)$ & 23 & This work \\
\hline
\end{tabular}

${ }^{\mathrm{a}}$ In the case of the cation, the potential energy barrier along the torsional coordinate was described by a gaussian function the height and width of which are determined by the parameters $A$ and $c$, respectively (see text for more details).

${ }^{\mathrm{b}} V_{9}=0.2 \mathrm{~cm}^{-1}$.

Fourier-series expansion

$V(\alpha)=\frac{V_{N}}{2}(1-\cos N \alpha)+\frac{V_{2 N}}{2}(1-\cos 2 N \alpha)+\ldots$,

with $N=3$. In the case of the $\mathrm{CH}_{2}$ torsion, we use similar expressions, the only differences being the definition of the torsional angle, which we label $\theta$ as defined in Fig. 1(d), and the period of the potential function, which is given by $2 \pi / N$ with $N=2$.

The one-dimensional Schrödinger equation corresponding to Eq. (1) was solved numerically using a discrete variable representation ${ }^{41,42}$ on a equidistant grid of 51 points over a range of $2 \pi$ and a calculation of $I_{\alpha}$ and $I_{g}$ in the way implemented by Makarewicz in Ref. 43. Initial calculations relied on the equilibrium geometry of the cation optimized $a b$ initio at the level of UMP2/3-611G(2d,p).

Attempts at fitting the potential parameters to the vibrational term energies observed experimentally retaining only the first two terms of the expansion in Eq. (4) revealed that a reasonable agreement with the experimental observations can only be reached if the ratio $\left|V_{2 N} / V_{N}\right|$ exceeds the value of $20 \%$, the parameter $V_{2 N}$ being negative. The large negative value of $V_{2 N}$ signifies that the potential energy surface along each torsional coordinate has a flat bottom and implies that higher-order terms should be retained in the Fourier-series expansion. Because only the fundamental and the first overtone of $v_{21}$ and $v_{20}$ are observed in most spectra, the experimental data are insufficient to reliably determine the potential parameters $V_{i N}$. Instead of using Eq. (4), the potential barriers along the torsional motion of the $\mathrm{CH}_{3}$ or $\mathrm{CH}_{2}$ group were described as sums of Gaussian functions

$$
f(x)=A \sum_{b} \exp \left(\frac{-(x-b)^{2}}{2 c^{2}}\right),
$$

where $A$ represents the height of the barriers, $b$ their central positions and $c$ their width. To obtain a periodic potential, the parameter $b$ was given the values $\pm 60^{\circ}$ and $\pm 180^{\circ}$ in the case of the methyl torsion and $\pm 90^{\circ}$ and $\pm 270^{\circ}$ in the case of the methylene torsion, and the calculations were performed in the intervals $-180^{\circ} \leq \alpha \leq+180^{\circ}$ and $-90^{\circ} \leq \theta \leq+270^{\circ}$, respectively.

The advantage of Eq. (5) is that each potential is only described by two potential parameters $A$ and $c$. $A$ and $c$ were adjusted until a good agreement with the experimental vibrational wave numbers was obtained. The optimized values of the potential parameters are presented in Table $\mathrm{V}$ and the corresponding calculated vibrational wave numbers of the torsional sublevels are compared with the experimental values in Table II. The calculated positions are also indicated by vertical bold lines in Fig. 4 to facilitate the comparison with the experimental observations. The transition intensities were not calculated because the bands $20_{0}^{v}$ and $21_{0}^{v}$ with odd $v$ values derive their intensities from vibronic interactions, as explained in Subsection III E. The height of the vertical bold lines in Fig. 4 was thus chosen so as to match the experimentally observed intensities.

With one set of parameters, $A=400 \mathrm{~cm}^{-1}$ and $c=17^{\circ}$, it was possible to reproduce satisfactorily the progressions associated with $v_{21}$ for all isotopomers, i.e. more than 10 line positions, as shown in Fig. 4. The agreement between the results of our one-dimensional calculations and the experimental results is overall very satisfactory, the only exception being the $21^{2}$ level of $\mathrm{CH}_{3} \mathrm{CHCD}_{2}^{+}$, the position of which appears to be overestimated by the calculations. We thus conclude that our one-dimensional model is likely to predict reliable order-of-magnitude estimates of the tunneling splittings. The predicted tunneling splitting of the origin $\left(0.14 \mathrm{~cm}^{-1}\right)$ and the $21^{1}$ level $\left(1.6 \mathrm{~cm}^{-1}\right)$ are too small to be observed at our spectral resolution; the predicted splitting of the $21^{2}$ level $\left(9.5 \mathrm{~cm}^{-1}\right)$ may be responsible for the broader and asymmetric lineshapes of the $21_{0}^{2}$ bands (Figs. 4(c) and 4(d), see also Fig. 7 in Sec. III E). The calculations also support our tentative assignment of the $21_{0}^{3}$ band in the spectrum of $\mathrm{CH}_{3} \mathrm{CHCD}_{2}$ (see Fig. 4(c)), and suggests that it corresponds to a transition to the tunneling component of e symmetry. 


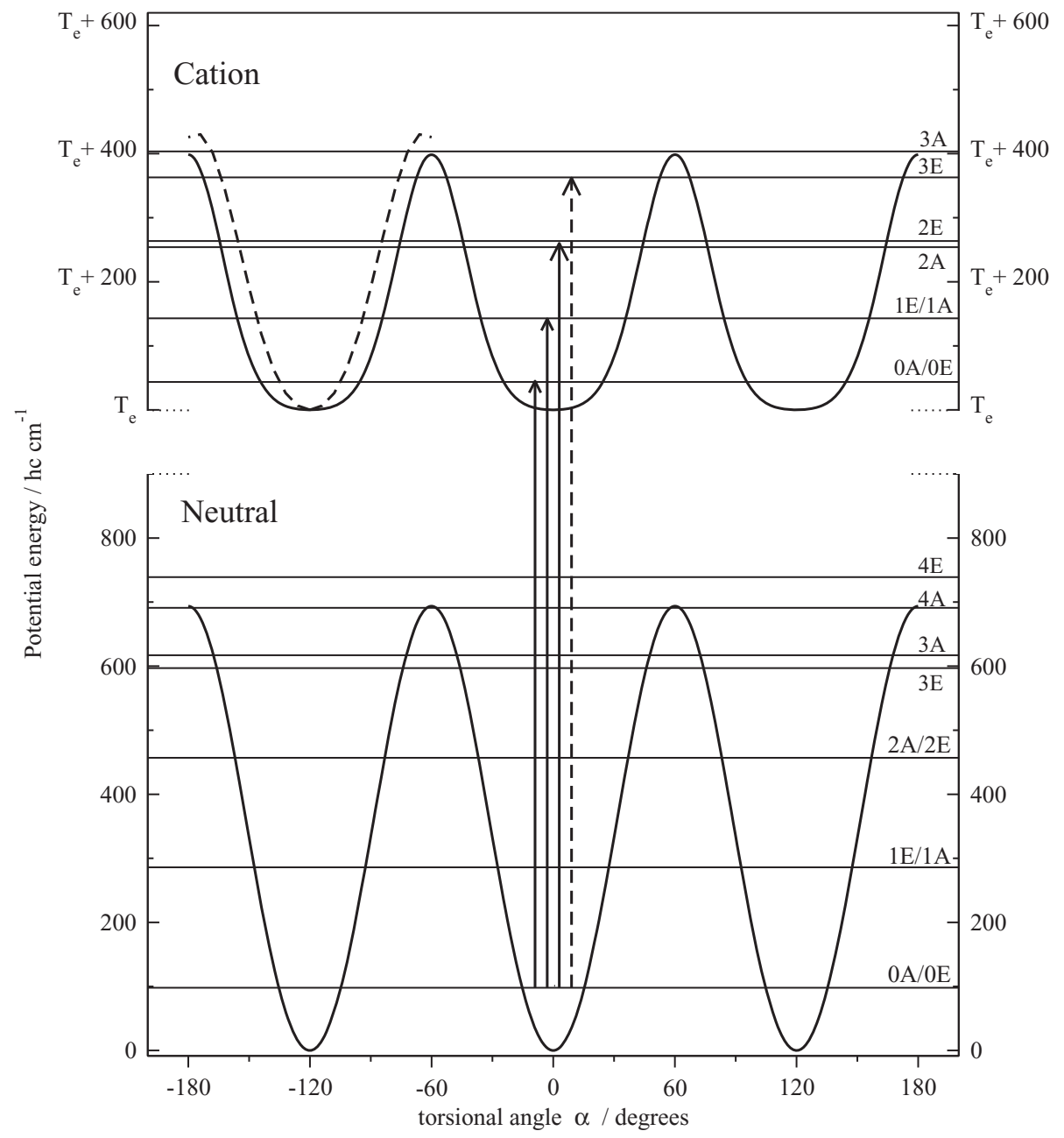

FIG. 5. Potential energy function along the $\mathrm{CH}_{3}$ torsional motion and $\mathrm{CH}_{3}$ torsional levels of propene in its ground neutral (Refs. 6 and 13) and ground cationic state (see Tables II and V). The arrows depict the transitions from the ground electronic state $\mathrm{Co}_{3} \mathrm{CHCH}_{2}$ to the ground electronic state of $\mathrm{CH}_{3} \mathrm{CHCH}_{2}^{+}$that were observed experimentally. The dashed arrow depicts the transition from $v^{\prime \prime}=0$ to the lower component of the $v^{+}=3$ vibrational level which was only observed in the photoelectron spectrum of $\mathrm{CH}_{3} \mathrm{CHCD}_{2}$ (at a different position). For comparison, the fully relaxed ab initio potential energy along the methyl coordinate calculated at the UMP2/6-311G(2d,p) level without zero-point-energy corrections is shown by a dashed line.

The potential energy functions along the methyl-torsion coordinate of the neutral species and the cation are displayed in the lower and upper panels of Fig. 5, respectively. Ionization out of the double bond leads to a significant reduction of the barrier to $\sim 400 \mathrm{~cm}^{-1}$ and to a more pronounced flat-bottom nature of the potential energy function near the minima, which suggests that the torsion of the methyl group around the top axis is almost free in a region of more than \pm 10 degrees around the equilibrium position. On the lefthand side of the upper panel of Fig. 5, the potential energy function calculated $a b$ initio at the UMP $2 / 6-311 \mathrm{G}(2 \mathrm{~d}, \mathrm{p})$ level without including zero-point-energy corrections is displayed with a dashed line. The barrier height is estimated to be $429 \mathrm{~cm}^{-1}$ which is in good agreement with the barrier height of $400 \mathrm{~cm}^{-1}$ resulting from our one-dimensional analysis. However, the $a b$ initio calculations do not reproduce the large widths of the potential wells predicted by our onedimensional model.

The coefficients of the Fourier-series expansion [Eq. (4)] were determined by a fit to a set of 69 points calculated according to Eq. (5) with $A=400 \mathrm{~cm}^{-1}$ and $c=17^{\circ}$ in the interval $-60^{\circ} \leq \alpha \leq 60^{\circ}$. The results of the fit are $V_{3}$ $=381.9 \pm 0.1 \mathrm{~cm}^{-1}, V_{6}=-117.9 \pm 0.1 \mathrm{~cm}^{-1}, V_{9}=16.66$ $\pm 0.02 \mathrm{~cm}^{-1}$, and $V_{12}=-1.088 \pm 0.020 \mathrm{~cm}^{-1}$. These results explain why our attempts at determining the potential parameters of Eq. (4) remained unsuccessful. The same procedure was followed to estimate the potential energy function along the methylene torsion. However, it was not possible to reproduce the experimentally observed positions of all different propene isotopomers with the same set of potential parameters. For the three $\mathrm{CH}_{2}$-containing isotopomers, the optimal values of the potential parameters were found to be $A=8000 \mathrm{~cm}^{-1}$ and $c=23^{\circ}$, whereas for the two $\mathrm{CD}_{2}$ containing isotopomers a reasonable agreement with the experimental results could only be obtained by increasing the barrier height to $8900 \mathrm{~cm}^{-1}$ keeping the value of $c$ unchanged. The potential parameters are summarized in Table $\mathrm{V}$ and the calculated positions of the methylene torsional levels are compared to the experimental results in Table II and are also indicated with vertical lines in Fig. 4 to facilitate the comparison.

The potential energy functions resulting from our onedimensional analysis of the methylene torsion of the propene 


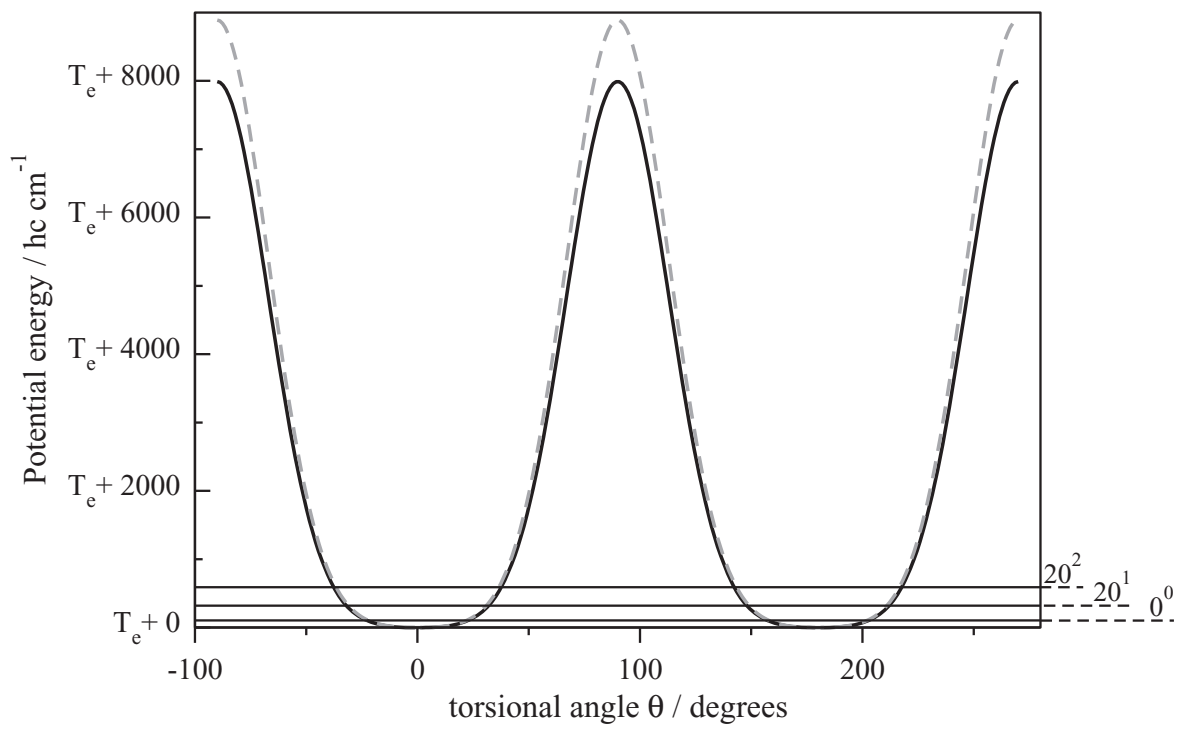

FIG. 6. Potential energy functions along the $\mathrm{CH}_{2}$ torsional coordinate of the propene radical cation depicted as full (dashed) lines for the $\mathrm{CH}_{2}-\left(\mathrm{CD}_{2}-\right)$ containing isotopomers. The lowest $\mathrm{CH}_{2}$-torsional levels calculated for the undeuterated species are indicated by horizontal lines.

radical cation are depicted in Fig. 6 as full (dashed) lines for the $\mathrm{CH}_{2-}\left(\mathrm{CD}_{2}-\right)$ containing isotopomers. The calculations indicate that the tunneling splittings resulting from the methylene torsion are negligible at our spectral resolution in the energy range studied experimentally.

\section{E. Vibronic coupling}

The observation of the $20_{0}^{v}$ and $21_{0}^{v^{\prime}}$ torsional bands with odd values of $v$ and $v^{\prime}$ in the photoelectron spectrum of propene indicates the presence of vibronic interactions. Indeed, these bands have zero Franck-Condon factors. Vibronic interactions had also to be invoked to explain the prominent central rotational branch with $\Delta K_{a}=K_{a}^{+}-K_{a}^{\prime \prime}=0$ and $\Delta N=N^{+}-N^{\prime \prime}=0$ in the spectrum of the $0_{0}^{0}$ origin bands of the $\widetilde{\mathrm{X}}^{+} \leftarrow \widetilde{\mathrm{X}}$ photoionizing transitions of $\mathrm{CH}_{3} \mathrm{CHCH}_{2}$ and $\mathrm{CD}_{3} \mathrm{CDCD}_{2}$, which correspond to the ejection of an electron from the outermost molecular orbital of $a^{\prime \prime}$ symmetry. This orbital has a nodal plane containing the three carbon atoms, and its single-center expansion consists primarily of $\left(\ell^{\prime \prime}=1, \lambda^{\prime \prime}= \pm 1\right),\left(\ell^{\prime \prime}=2, \lambda^{\prime \prime}= \pm 1\right)$ and $\left(\ell^{\prime \prime}=2, \lambda^{\prime \prime}\right.$ $= \pm 2$ ) contributions, $\lambda^{\prime \prime}= \pm 0$ being forbidden by symmetry (see Ref. 30 for a complete discussion). In the orbital ionization approximation, ${ }^{44}$ the rotational selection rules can be expressed as $\left(\Delta N, \Delta K_{a}\right)=\left(\ell^{\prime \prime}, \lambda^{\prime \prime}\right)$. The observation of a $\Delta K_{a}=0$ branch thus indicates an admixture of an $a^{\prime}$ molecular orbital contribution at geometries deviating from $C_{\mathrm{s}}$ symmetry.

The rotational contours of the bands observed in Figs. 2 and 4 , in particular those of the forbidden $20_{0}^{1}$ and $21_{0}^{1}$ bands, contain additional information on the vibronic interaction. The relevant regions of the spectra of $\mathrm{CH}_{3} \mathrm{CHCD}_{2}$ and $\mathrm{CD}_{3} \mathrm{CHCH}_{2}$, in which the $20_{0}^{1}$ band is observed as isolated band, are displayed on an enlarged scale in Fig. 7. The figure reveals that the $20_{0}^{1}$ and $21_{0}^{1}$ bands have a similar asymmetric lineshape with a narrow spike on its low-frequency side that differs from the more symmetric lineshapes of the allowed $21_{0}^{2}$ and other Franck-Condon allowed bands.
As explained in Refs. 25 and 44, the rotational structure of Franck-Condon forbidden transitions directly reflects the symmetry and molecular-orbital structure of the electronic state that is coupled by vibronic interactions. The rotational contours of the $20_{0}^{1}$ and $21_{0}^{1}$ bands could be modelled by assuming that the vibronic coupling is primarily to the $\widetilde{\mathrm{A}}^{+}$state which is formed by removing an electron from the $10 a^{\prime}$ orbital depicted in the inset of Fig. 7. Characteristic features of this orbital are the significant $\lambda^{\prime \prime}=0$ contributions and the slow convergence of the single-center expansion with $\ell^{\prime \prime}$ and $\lambda^{\prime \prime}$, which result in the sharp central feature and several $\Delta K_{a}$ branches on both sides of this spectral feature (see Fig. 7).

Compared to the relative branch intensities $\left(\Delta N,\left|\Delta K_{a}\right|\right)=\left(\ell^{\prime \prime},\left|\lambda^{\prime \prime}\right|\right) \quad$ of $\quad(0,0)=0.4, \quad(1,1)=0.3$, $(2,1)=1.3$ and $(2,2)=0.6$ used to reproduce the rotational structure of the $0_{0}^{0}$ origin band ${ }^{30}$ and of other Franck-Condon allowed bands, relative branch intensities of $(0,0)=0.3$, $(1,0)=0.3, \quad(1,1)=0.5, \quad(2,0)=0.3, \quad(2,1)=0.4 \quad$ and $(2,2)=0.8$ were used to reproduce the contours of the Franck-Condon forbidden $20_{0}^{1}$ and $21_{0}^{1}$ bands. The $\left|\lambda^{\prime \prime}\right|=1$ components correspond to orbital contributions with a $y z$ nodal plane, because there cannot be an $x z$ nodal plane by symmetry (see inset of Fig. 7). In the calculations presented in Fig. 7, the rotational constants of the neutral and cationic species were held fixed to either the experimentally determined values ${ }^{9}$ when available or to the values predicted by $a b$ initio calculations at the MP2/6-311G(2d,p) level. The calculated rotational contours of the $21_{0}^{1}$ and $20_{0}^{1}$ bands of $\mathrm{CH}_{3} \mathrm{CHCD}_{2}$ and of the $20_{0}^{1}$ band of $\mathrm{CD}_{3} \mathrm{CHCH}_{2}$ (orange traces in Fig. 7) reproduce the experimentally observed contours well and show the characteristic features of transitions to cationic vibronic levels of $a^{\prime}$ symmetry discussed above. The calculated contours of the $20_{0}^{2}$ bands of $\mathrm{CD}_{3} \mathrm{CHCH}_{2}$ and $\mathrm{CH}_{3} \mathrm{CHCD}_{2}$ (dashed magenta traces) are overall broader. Whereas in the former case the calculated and experimental spectra resemble each other closely, the calculated spectrum of $\mathrm{CH}_{3} \mathrm{CHCD}_{2}$ appears narrower than the experimental 


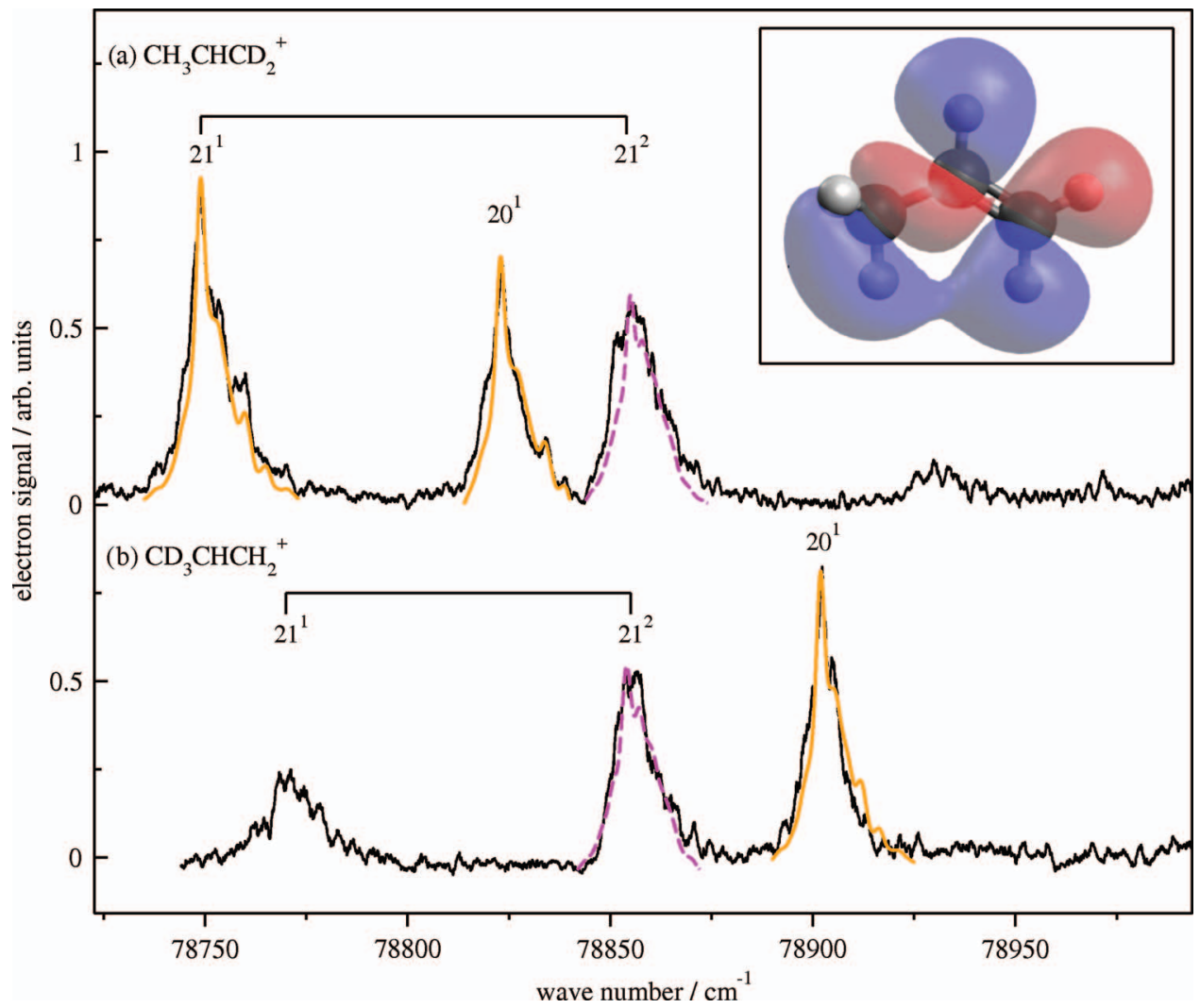

FIG. 7. Enlarged view of the PFI-ZEKE photoelectron spectra of (a) $\mathrm{CH}_{3} \mathrm{CHCD}_{2}$ and (b) $\mathrm{CD}_{3} \mathrm{CHCH}_{2}$ at low energies. The calculated rotational contours of the bands having $a^{\prime \prime}\left(a^{\prime}\right)$ vibrational symmetry are shown with a solid orange line (dashed magenta line). The inset in a) shows a schematic diagram of the $10 a^{\prime}$ orbital of neutral propene based on a Hartree-Fock calculation.

spectrum. We attribute this difference to the tunneling splitting of the $21^{2}$ torsional level of $\mathrm{CH}_{3} \mathrm{CHCD}_{2}^{+}$, which is significantly higher $\left(\sim 8.6 \mathrm{~cm}^{-1}\right)$ than in $\mathrm{CD}_{3} \mathrm{CHCH}_{2}^{+}$ $\left(\sim 1.5 \mathrm{~cm}^{-1}\right)$ according to our one-dimensional calculations (see Table II).

The comparison of calculated and experimental contours does not only confirm the vibrational assignments made on the basis of isotopic substitution, it also indicates that the two torsional modes mediate the vibronic interactions between the $\widetilde{\mathrm{X}}^{+2} \mathrm{~A}^{\prime \prime}$ and $\widetilde{\mathrm{A}}^{+2} \mathrm{~A}^{\prime}$ electronic states. This vibronic interaction is probably one of the reasons for the flat-bottom nature of the effective one-dimensional torsional potentials derived in Subsection III D.

\section{SUMMARY AND CONCLUSIONS}

The PFI-ZEKE photoelectron spectra of the $\widetilde{\mathrm{X}}^{+} \leftarrow \widetilde{\mathrm{X}}$ photoionizing transition of propene and several deuterated isotopomers have enabled us to obtain new information on the low-frequency modes of the propene cation, in particular on the methyl $\left(v_{21}\right)$ and methylene $\left(v_{20}\right)$ torsions, which are observed as vibrational progressions with a characteristic, strong positive anharmonicity. The systematic analysis of isotopic shifts resulting from deuteration at specific carbon sites was essential in deriving unambiguous assignments.

Upon removal of an electron from the $\pi_{\mathrm{CC}}$ bonding orbital, the flexibility of propene along both the methyl and methylene torsional modes is considerably enhanced. The following conclusions can be drawn from an analysis of the observed positions of the torsional levels with simple onedimensional models:

(1) The potential barriers separating equivalent equilibrium structures along the methyl and methylene torsion in the cation are much reduced compared to the neutral molecule to $\sim 400 \mathrm{~cm}^{-1}\left(\sim 700 \mathrm{~cm}^{-1}\right.$ in neutral propene) in the case of the methyl torsion and $\sim 8000 \mathrm{~cm}^{-1}\left(\gg 10000 \mathrm{~cm}^{-1}\right.$ in neutral propene) in the case of the methylene torsion, and so are the corresponding vibrational frequencies. The eclipsed conformation is the most stable both in the neutral and the cation. The magnitude of the reduction of the barrier along the methyl torsion corresponds closely to that predicted theoretically by Dorigo et al. ${ }^{18}$ As pointed out by these authors, the dominant effect favoring the eclipsed conformation is the repulsion of the methyl $\mathrm{C}-\mathrm{H}$ and the central $\mathrm{C}-\mathrm{H}$ bonds, which destabilizes the staggered conformation.

(2) The one-dimensional potential energy functions that best describe the experimental observations are unusually flat near the equilibrium geometries and give rise to pronounced positive anharmonicities. A similar, though less pronounced effect observed in the methyl torsion of neutral propene has been attributed to the fact that this torsional mode is not localized but involves motions of the $\mathrm{CH}_{2}$ group and the central $\mathrm{CH}$ bond resulting in a flat-bottom effective one-dimensional minimum-energy path and a negative $V_{6}$ coefficient. ${ }^{13}$ In the propene radical cation, the vibronic coupling to the $\widetilde{\mathrm{A}}^{+2} \mathrm{~A}^{\prime}$ state probably contributes to accentuate the flat-bottom nature of the effective one-dimensional torsional potentials. 
(3) The observation of the $20_{0}^{1}$ and $21_{0}^{1}$ bands, which are forbidden in first approximation, indicates that vibronic interaction of the $\widetilde{\mathrm{X}}^{+2} \mathrm{~A}^{\prime \prime}$ ground state of the cation with higherlying electronic states of $\mathrm{A}^{\prime}$ symmetry mediated by the methyl and methylene torsions are important. This observation corroborates the observation made in our previous study of the rotational structure of the origin band of the photoelectron spectrum of $\mathrm{CH}_{3} \mathrm{CHCH}_{2}$ and $\mathrm{CD}_{3} \mathrm{CDCD}_{2}$ which could only be explained by invoking vibronic interactions. ${ }^{30}$ The analysis of the rotational contours of the "forbidden" $20_{0}^{1}$ and $21_{0}^{1}$ bands indicates that the vibronic coupling to the $\widetilde{\mathrm{A}}^{+2} \mathrm{~A}^{\prime}$ state of the cation, which is formed by removing an electron from the $10 a^{\prime}$ molecular orbital of the neutral molecule, plays an important role and is mediated by the torsional vibrational motions. More generally, our results imply that the treatment of large-amplitude torsional motions and conformational changes in radical cations with unsaturated backbones should include excited electronic configurations and vibroniccoupling effects.

The one-dimensional analysis of the methyl and methylene torsions in the propene radical cation represents a first step towards a full characterization of the vibronic interactions and large-amplitude motions in the $\widetilde{\mathrm{X}}^{+2} \mathrm{~A}^{\prime \prime}$ ground state. High-level $a b$ initio calculations including vibronic interactions and experiments at still higher resolution would be particularly useful to reach this goal and also to assess the limits of the simple models employed in our analysis.

\section{ACKNOWLEDGMENTS}

We thank G. Grassi and R. Ulrich (both ETH Zurich) for the synthesis of the partially deuterated compounds, Dr. A. M. Schulenburg (ETH Zurich) for recording the low-energy region of the photoelectron spectrum of $\mathrm{CH}_{3} \mathrm{CHCH}_{2}$ and Dr. M. Schäfer (ETH Zurich) for useful discussions. This work is supported financially by the Swiss National Science Foundation under Project No. 200020-135342.

\footnotetext{
${ }^{1}$ N. Marcelino, J. Cernicharo, M. Agúndez, E. Roueff, M. Gerin, J. MártinPintado, R. Mauersberger, and C. Thum, Astrophys. J. 665, 127 (2007).

${ }^{2}$ E. Roueff and E. Herbst, J. Phys.: Conf. Ser. 192, 012008 (2009).

${ }^{3}$ W. G. Fateley and F. A. Miller, Spectrochim. Acta 19, 611 (1963).

${ }^{4}$ K. D. Möller, A. R. De Meo, D. R. Smith, and L. H. London, J. Chem. Phys. 47, 2609 (1967).

${ }^{5}$ B. Silvi, P. Labarbe, and J. P. Perchard, Spectrochim. Acta, Part A 29, 263 (1973).

${ }^{6}$ J. R. Durig, G. A. Guirgis, and S. Bell, J. Phys. Chem. 93, 3487 (1989).

${ }^{7}$ D. R. Lide, Jr., and D. E. Mann, J. Chem. Phys. 27, 868 (1957).
}

${ }^{8}$ D. R. Lide, Jr., and D. Christensen, J. Chem. Phys. 35, 1374 (1961).

${ }^{9}$ E. Hirota and Y. Morino, J. Chem. Phys. 45, 2326 (1966).

${ }^{10}$ E. Hirota, J. Chem. Phys. 45, 1984 (1966).

${ }^{11}$ G. Wlodarczac, J. Demaison, N. Heineking, and A. G. Császár, J. Mol. Spectrosc. 167, 239 (1994).

${ }^{12}$ J. C. Pearson, K. V. L. N. Sastry, E. Herbst, and F. C. De Lucia, J. Mol. Spectrosc. 166, 120 (1994).

${ }^{13}$ L. Goodman, J. Leszczynski, and T. Kundu, J. Am. Chem. Soc. 115, 11991 (1993).

${ }^{14}$ A. B. Burrill and P. M. Johnson, J. Chem. Phys. 115, 133 (2001).

${ }^{15}$ J. P. Lowe, Prog. Phys. Org. Chem. 6, 1 (1968).

${ }^{16}$ R. Hoffman, Acc. Chem. Res. 4, 1 (1971).

${ }^{17}$ R. M. Pitzer, Acc. Chem. Res. 16, 207 (1983).

${ }^{18}$ A. E. Dorigo, D. W. Pratt, and K. N. Houk, J. Am. Chem. Soc. 109, 6591 (1987).

${ }^{19}$ G. Reiser, W. Habenicht, K. Müller-Dethlefs, and E. W. Schlag, Chem. Phys. Lett. 152, 119 (1988).

${ }^{20}$ H.-J. Dietrich, K. Müller-Dethlefs, and L. Y. Baranov, Phys. Rev. Lett. 76, 3530 (1996).

${ }^{21}$ U. Hollenstein, R. Seiler, H. Schmutz, M. Andrist, and F. Merkt, J. Chem. Phys. 115, 5461 (2001).

${ }^{22}$ F. Merkt, S. Willitsch, and U. Hollenstein, "High-resolution photoelectron spectroscopy," in Handbook of High-Resolution Spectroscopy, edited by M. Quack and F. Merkt (Wiley, Chichester, 2011).

${ }^{23}$ E. C. Richard, R. A. Walker, and J. C. Weisshaar, J. Chem. Phys. 104, 4451 (1996).

${ }^{24}$ K. H. Fung, H. L. Selzle, and E. W. Schlag, J. Phys.Chem. 87, 5113 (1983).

${ }^{25}$ S. Willitsch, U. Hollenstein, and F. Merkt, J. Chem. Phys. 120, 1761 (2004).

${ }^{26}$ P. Wang, X. Xing, S. Y. Baek, and C. Y. Ng, J. Phys. Chem. A 108, 10035 (2004).

${ }^{27}$ K. Alnama, S. Boyé-Péronne, A.-L. Roche, and D. Gauyacq, Mol. Phys. 105, 1743 (2007).

${ }^{28}$ M. Lee, and M. S. Kim, J. Chem. Phys. 119, 12351 (2003).

${ }^{29}$ Y. J. Bae, M. Lee, and M. S. Kim, J. Chem. Phys. 123, 044306 (2005)

${ }^{30}$ K. Vasilatou, M. Schäfer, and F. Merkt, J. Phys. Chem. A 114, 11085 (2010).

${ }^{31}$ X. Xing, M.-K. Bahng, P. Wang, K.-C. Lau, S. Y. Baek, and C. Y. Ng, J. Chem. Phys. 125, 133304 (2006).

${ }^{32}$ M. E. Jacox and W. E. Thompson, J. Chem. Phys. 134, 064321 (2011).

${ }^{33}$ P. Rupper and F. Merkt, Rev. Sci. Instrum. 75, 613 (2004).

${ }^{34}$ J. Barluenga, M. Yus, J. M. Concellón, and P. Bernad, J. Org. Chem. 46, 2721 (1981).

${ }^{35}$ J. B. Lambert, E. C. Chelius, W. J. Schulz Jr., and N. E. Carpenter, J. Am. Chem. Soc. 112, 3156 (1990).

${ }^{36}$ I. Farkas, and H. Pfander, Helv. Chim. Acta 73, 1980 (1990).

${ }^{37}$ D. R. Borst, and D. W. Pratt, J. Chem. Phys. 113, 3658 (2000).

${ }^{38}$ W. Gordy, and R. L. Cook, Microwave Molecular Spectra (Wiley, New York, 1984).

${ }^{39}$ D. R. Herschbach, J. Chem. Phys. 31, 91 (1959).

${ }^{40}$ A. Bauder, "Fundamentals of rotational spectroscopy," in Handbook of High-Resolution Spectroscopy, edited by M. Quack and F. Merkt (Wiley, Chichester, 2011).

${ }^{41}$ R. Meyer, J. Chem. Phys. 52, 2053 (1970).

${ }^{42}$ R. Meyer, J. Mol. Spectrosc. 76, 266 (1979).

${ }^{43}$ J. Makarewicz, J. Mol. Spectrosc. 176, 169 (1996).

${ }^{44}$ S. Willitsch and F. Merkt, Int. J. Mass Spectrom. 245, 14 (2005).

${ }^{45}$ C. E. Souter and J. L. Wood, J. Chem. Phys. 52, 674 (1970). 